This document was prepared in conjunction with work accomplished under Contract No. DE-AC09-96SR18500 with the U. S. Department of Energy.

\title{
DISCLAIMER
}

This report was prepared as an account of work sponsored by an agency of the United States Government. Neither the United States Government nor any agency thereof, nor any of their employees, nor any of their contractors, subcontractors or their employees, makes any warranty, express or implied, or assumes any legal liability or responsibility for the accuracy, completeness, or any third party's use or the results of such use of any information, apparatus, product, or process disclosed, or represents that its use would not infringe privately owned rights. Reference herein to any specific commercial product, process, or service by trade name, trademark, manufacturer, or otherwise, does not necessarily constitute or imply its endorsement, recommendation, or favoring by the United States Government or any agency thereof or its contractors or subcontractors. The views and opinions of authors expressed herein do not necessarily state or reflect those of the United States Government or any agency thereof. 
WSRC-TR-2005-00435

\title{
Effect of Scratches on Pinch Welds
}

\author{
P.S. Korinko
}

October 2005

SRNL SAVANNAH RIVER NATIONAL LABORATORY, AIKEN, SC 29808 Westinghouse Savannah River Company

Prepared for the U.S. Department of Energy under Contract DE-AC09-96SR1850 
WSRC-RP-2005-00435

MST

MATERIALS SCIENCE and TECHNOLOGY

$\begin{array}{ll}\text { Keywords: } & \text { Stainless steel } \\ & \text { Fill Stems } \\ & \text { Pinch welds } \\ \text { Retention: } & \text { Permanent }\end{array}$

\title{
Effect of Scratches on Pinch Welds
}

\author{
P.S. Korinko \\ Materials Compatibility and Welding Technology Group
}

ISSUED: October 2005

SRNL SAVANNAH RIVER NATIONAL LABORATORY, AIKEN, SC 29808 Westinghouse Savannah River Company

Prepared for the U.S. Department of Energy under Contract DE-AC09-96SR18500 
Effect of Scratches on Pinch Welds Page iv WSR-TR-2005-00435

3

Document: $\quad$ WSRC-TR-2005-00435

Title: $\quad$ Effect of Scratches on Pinch Weld

APPROVALS

10-12-2005

P.S. Korinko, Author

Date

Materials Compatibility and Welding Technology

W.L. West via electronic concurrence

$11-9-2005$

W.L. West, Technical Reviewer

Date

Reservoir Systems Engineering

S.L. $\overline{\text { West, }}$ Manager

$10 / 12 / 2005$

Materials Compatibility and Welding Technology

Date 
Table of Contents

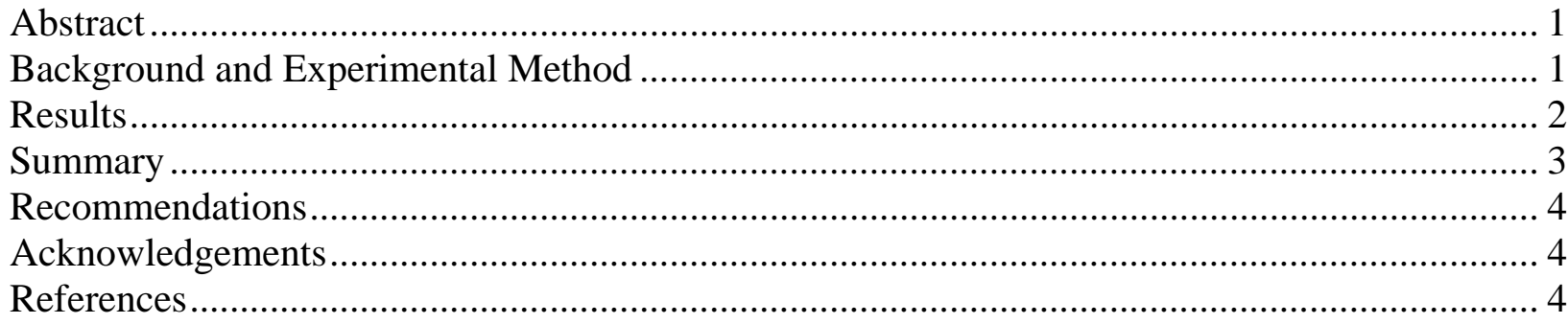

List of Tables

Table 1. Weld Conditions and machine data ....................................................................... 5

Table 2. Weld quality information .................................................................................... 5

List of Figures

Figure 1. Weld equipment used (a) Weld head (b) displacement sensor and placement (c) assembly for welding (d) simulated LF-7 mass (e) fully assembled fixture including confining dies, "reservoir" and basket. ..................................................................... 6

Figure 2. Forward looking borescope images (a) X0034 (b) X0039 (c) X0042 and (d) X0047 ... 7

Figure 3. Side looking borescope images (a) X0034 (b) X0039 (c) X0042 and (d) X0047......... 8

Figure 4. Unwrapped images using the True Color Tube Borescope Inspection System (TCTBIS) for (a) X0034 (b) X0039 (c) X0042 and (d) X0047. 9

Figure 5. Forward looking borescope image after welding of (a) X0047 $0^{\circ}$ (b) X0034 $45^{\circ}$ (c) X0039 $45^{\circ}$ and (d) X0042 90. . Note target values are reported, not actual.

Figure 6. Face and side view radiographs of scratched and welded stems (a) X0034 (b) X0039 (c) X0042 (d) X0047. Note the presence of fiduciary marks in image on lower right side of all these images. These are used to determine closure length, wall thickness, alignment, etc.

Figure 7. Transverse cross sections in the crow's foot of weld in stem X0034 at (a) 50X (b) $100 \mathrm{X}$ (c) $200 \mathrm{X}$ and (d) $500 \mathrm{X}$ magnifications, scratch at $45^{\circ}$ from axis, at 0.02 " from end of weld, (e) 200X, (f) 500X and (g) 1000X at a distance about 0.06 from end of weld, (h) 50X (i) $100 \mathrm{X}$ and (j) $200 \mathrm{X}$ and (k) $500 \mathrm{X}$ at the weld center. See Figure 5 for nominal end of weld and note that the bond line does not exhibit any gross disruption, however, there is evidence of the prior scratch in two of the three axial locations as indicated by the arrows.14

Figure 8. Transverse cross sections of welds at magnifications of (a) 50X (b) 100X (c) 200X (d) $500 \mathrm{X}$ (e) $500 \mathrm{X}$ at 0.02 inch from end of weld and at (f) 500X and (g) $1000 \mathrm{X}$ at 0.06 from end of weld and at (h) 200X and (i) 500X at the center of the weld of sample X0039. The arrow in (d) highlights nonlinear indication attributed to scratch.................................... 16

Figure 9. Transverse cross sections of welds at magnification of (a) 50X (b) 100X (c) $200 \mathrm{X}$ and (d) $500 \mathrm{X}$ at 0.02 from end of weld and (e) $200 \mathrm{X}$ (f) $500 \mathrm{X}$ and (g) $1000 \mathrm{X}$ at 0.06 inch from the end of the weld and at (h) 50X (i) 100X (j) 200X and (k) 500X in the center of the weld for sample X0042. Note the there is a detectable disruption in the bond line in all three axial locations, as highlighted by arrows, however it does not appear to adversely affect the weld. 
Figure 10. Transverse cross sections at magnifications of (a) 50X (b) 100X (c) 200X (d) 500X and (e) $1000 \mathrm{X}$ at 0.02 from end of weld (f) $500 \mathrm{X}$ (g) $1000 \mathrm{X}$ at 0.06 from end of weld and (h) 200X (i) 500X at the weld center of sample X0047. Note that some disruption, highlighted by the arrows, of the bond line is evident in all three axial locations but little effect on the weld is apparent.

Figure 11. Sample X0039, nitric acid etchant showing recrystallization and grain growth. The evidence of the scratch is visible at 100X and higher magnifications. (a) 50X (b) 100X (c) 100X (d) 200X (e) 500X and (f) 1000X magnifications.

Figure 12. Transverse cross-sections of the tubes showing the amount of raised metal and the depth of the scratch (a) X0034 50X (b) X0034 100X (c) X0034 500X (d) X0039 50X (e) X0039 100X, and (f) X0039 500X. 
Effect of Scratches on Pinch Welds Page 1 WSRC-TR-2005-00435

\section{Effect of Scratches on Pinch Welds}

\section{Abstract}

Fill stems for tritium reservoirs have stringent scratch requirements such that any indications that appear to have depth are cause for rework or rejection. A scoping study was undertaken to evaluate the effect of scratches approximately 0.0015 to 0.002 inch deep on the fitness for service and bond quality. The stems were characterized using borescope before and after welding. The four stems were welded with near optimal weld parameters, proof tested, and examined metallographically. The stems were radiographed, proof tested, and examined metallographically. The scratches did not adversely affect (1) the weld integrity based on radiography, (2) the ability to withstand the proof pressure, and (3) the weld quality based on metallographic cross-sections. Based on these limited results at a nominal weld current, the weld process is very robust. It may be able to recover from manufacturing defects and inspection anomalies worse than those expected for typical fill stem manufacturing processes; additional testing specific to each application over a range of weld heats is needed to verify applicability of these results.

\section{Background and Experimental Method}

Fill stems for tritium reservoirs have stringent scratch and internal bore inspection criteria. One issue with the inspection criteria is that it often leaves a burnish mark that appears as if it may have "depth". The Kansas City Plant (KCP) rejects stems that exhibit these types of indications. However, the actual measured depth of scratches observed to date has been in the tens of a millionth of an inch. A scoping study was undertaken to examine the effect that scratches approximately 0.001 inch deep have on the pinch weld. The scratches were made at KCP by a specialized tool made of tungsten carbide that was inserted in the fully machined fill stem and that engaged one side of the tube. It dug a furrow and displaced metal at the tip of the tool and around the edges. The internal surface was characterized using a borescope before and after welding. Welds were oriented such that the scratch was nominally perpendicular, parallel, and at an angle of about $45^{\circ}$ to the electrode.

Welds were made using the SRNL pinch welder using nominal weld conditions at a force of 1250 lbs, a target current of $3700 \mathrm{~A}$, in voltage control mode, and 12 cycles. The welds were made in the vertical orientation with a simulated LF-7 mass and LF-7 fixturing. The weld head and fixturing are shown in Figure 1. The welds were made using an atmosphere of 2 ATM deuterium after evacuating the system to about -28 inches of water.

The samples were measured for thickness and width, radiographed for weld anomalies, closure length, and extrusion geometry, ultrasonically tested at KCP for comparison to normal welds, proof tested to $40 \mathrm{ksi}$, and examined metallographically. 


\section{Results}

The internal bore condition of the four stems is shown in Figures 2 and 3 for forward looking and side-looking borescope images, respectively. The scratches are located towards the top of the page and these images are about $1 / 4$ inch from the weld zone; the scratches were uniform the length of the fill stem. Two of each sample were Oakite cleaned and the other two were Nitradd cleaned and exhibited the expected lightly etched appearance. Note the raised metal on the side of the furrow and the burnish mark opposite the scratch. The linearity of the scratch and the presence of raised metal are apparent in the images from the True Color Tube Borescope Inspection System (TCTBIS) shown in Figure 4. The scratch was oriented at about $90^{\circ}$ from vertical and the burnish mark opposite the scratch is apparent. The scratches seem more prominent in stems X0039 and X0047 than in stems X0033 and X0042. The scratch depth and width were determined by KCP to be between 0.0014 and 0.0019 inch and .0025 to .004 inch, respectively.

The stems were welded using the conditions detailed in Table 1. The weld voltage, current and force were close to the desired target values. The post weld resistance is consistent with other welds in type 304L made using these conditions. All of the samples were welded within 10 amperes of the target. The weld thickness was consistent between samples, as expected for samples welded using nominally the same conditions and set-up.

The actual scratch orientation for the welds is shown in the forward looking borescope images shown in Figure 5. It is apparent that the target and actual weld orientation are not coincident due to the difficulty in precisely orienting the scratch relative to the axial serial number and maintaining this orientation while assembling the simulated reservoir into the weld fixture. The end of the welds have a consistent appearance, with no obvious defects, such as splits or voids, visible where the weld intersects the scratch.

Digital radiographs of the face and side view for each of the welds are shown in Figure 6. The scratches, indicated by the arrows, are visible in the side views of samples X0034 and X0047. The scratch is partially visible in the face view of X0039. The scratches are obvious in these images and appear as linear indications. The radiographs were interpreted in DP and samples X0039 and X0047 were reported to have split extrusions.

All of the samples were proof tested to 40,000 psi and held for 2 minutes per the standard proof testing methodology without leakage or failure.

The metallographic examinations were conducted about 0.02 inch from the end of the weld, about 0.06 inch from the end, and near the center of the pinch weld. Cross sections of the fill stems were also examined to characterize the scratch depth and amount of raised metal. The weld quality was determined from the cross sections, special attention was devoted to looking for laps and other weld anomalies. The micrographs for each weld cross section at the three axial locations are shown in Figures 7-10; not all the magnifications are include in these micrograph series since there was indistinct evidence of the scratches in many of the micrographs. The arrows on the micrographs indicate suspected evidence of the scratches. Figures $7 \mathrm{~g}$ and $7 \mathrm{i}$ show possible bond line disruptions at both axial locations of 0.06 inch and the center for sample 
X0034. Apparent bond line disruptions are visible in Figures 8d, 8g, and 8i for stem X0039, Figures 9d, 9e, and 9j for stem X0042, and in Figures 10e, 10g, and 10i for stem X0047 at all three axial locations. These indications are visible in large part because the bond line is not linear in these areas. The bond quality does not appear to be compromised though. Since these scratches were clean and since there is a significant amount of material flow, the scratches filled with metal and bonded adequately.

Weld sample X0039 was etched using nitric acid etchant over the oxalic acid to determine if the scratch may have impeded grain growth. The images are shown in Figure 11. The scratch is apparent near the center of the sample in Figure 11c, the nominal 100X magnification image. This area was further examined at higher magnifications, and while the disruption due to the scratch is visible, it does not appear to have adversely impacted grain growth across the interface. The grain structure is more clearly delineated with the nitric acid etchant. The grain size and distribution is consistent with that described in a weld evolution study that was recently completed, Ref. 1.

Samples X0034 and X0039 were examined in the tube bore section to show the extent of raised metal and the depth of the scratch, Figure 11. These two samples were selected based on the apparent difference in scratch depth observed in the borescope images in Figure 4. The depth of the scratches was measured from these images to be approximately 0.0016 and 0.002 ”, for X0034 and X0039, respectively. The height of the raised metal for each sample was approximately 0.0009 and 0.0005 , respectively. The depth of the burnish mark opposite the scratch was not measurable.

\section{Summary}

The scratches present in these stems well exceed the rejection limit for borescopic inspection and no depth was measured on the burnish mark opposite the scratch. The scratches were visible in the radiographs away from the welds but were not present as three dimensional defects in the welds. The scratches were between 0.0015 and 0.002 inch deep.

The presence of the scratches in the as machined tube did not adversely affect the stem weld integrity and its ability to withstand 40,000 psi for 2 minutes.

The scratches did not adversely affect the bond quality of the pinch welds which exhibited class 2 and one class 3 . The presence of the scratches was detected in the micrographs and were observed as non-linear indications in many of the cross sections. One scratch was associated with an oxide "star" in one of the three planes examined.

At nominal weld conditions, the process is robust enough to recover from manufacturing defects and inspection anomalies much larger than what is expected for typical fill stem production. 


\section{Recommendations}

In order to allow for less stringent inspection criteria with respect to linear indications and spiral indications of nominal depth, additional testing is warranted. These welds were made near the center of the weld window based on the closure length and presence of extrusion. Welds made at colder conditions are known to exhibit less displacement and deformation and may be prone to failure if there are significant defects. In addition, these scratches were very clean and mimicked machined surfaces, the effects of surface contamination was not considered for this screening study. Consequently, directed research is needed to ensure no significant degradation of weld properties are encountered if "scratches that exhibit depth" of discoloration are permitted for actual product. Finally, any change such as this requires Design Agency concurrence.

\section{Acknowledgements}

The author would like to express his thanks to K. Arnold and A. Estebenez of the KCP for providing scratched stems. C. Kestin was instrumental in providing bond ratings for the samples. He would like to recognize the contributions of the radiographers in DP for their quick turn around time for the inspection. He would finally like to recognize the efforts of Z. Nelson and V. Timmerman for the metallography.

\section{References}

1. WSRC-RP-2005-01762, Pinch Weld Evolution: A Phenomenological Model, P.S. Korinko and W.L. West, Westinghouse Savannah River Company, Savannah River Site, Sept. 2005. 


\section{Table 1. Weld Conditions and machine data}

\begin{tabular}{|c|c|c|c|c|c|c|c|c|c|c|c|c|}
\hline ID & Cleaning & Orient. & Voltage & Force & Pressure & $\begin{array}{l}\text { Preweld } \\
\mathrm{R}\end{array}$ & $\begin{array}{l}\text { Postweld } \\
\text { R }\end{array}$ & Current & Energy & Cycles & Voltage & $\begin{array}{l}\text { Net } \\
\text { disp. (in) }\end{array}$ \\
\hline $\mathrm{X0034}$ & Nitradd & 45 & 365.23 & 1248.00 & 108.40 & 0.2447 & 0.2130 & 3701.85 & 568.57 & 12 & 0.7886 & 0.0205 \\
\hline X0039 & Aqueous & 45 & 365.19 & 1251.04 & 108.65 & 0.2606 & 0.2167 & 3697.29 & 563.70 & 12 & 0.8012 & 0.0195 \\
\hline $\mathrm{X} 0042$ & Nitradd & 90 & 365.67 & 1250.82 & 108.65 & 0.2608 & 0.2132 & 3703.61 & 569.49 & 12 & 0.7898 & 0.0213 \\
\hline$\times 0047$ & Aqueous & 0 & 365.50 & 1248.25 & 108.41 & 0.2622 & 0.2142 & 3703.02 & 575.18 & 12 & 0.7930 & 0.0202 \\
\hline
\end{tabular}

\section{Table 2. Weld quality information}

\begin{tabular}{|c|c|c|c|c|c|c|c|c|c|}
\hline & Orient. & $\begin{array}{l}\text { Thickness } \\
\text { (in) }\end{array}$ & $\begin{array}{l}\text { Closure } \\
\text { length (in) }\end{array}$ & $\begin{array}{l}\text { Extrusion } \\
\text { length (in) }\end{array}$ & $\begin{array}{l}\text { Extrusion } \\
\text { ratio }\end{array}$ & $\begin{array}{l}\text { Proof test } \\
40 \mathrm{ksi}\end{array}$ & $\begin{array}{l}\text { Bond } \\
\text { rating* }\end{array}$ & $\begin{array}{l}\text { Bond } \\
\text { rating+ }\end{array}$ & Comments \\
\hline$\times 0034$ & 45 & 0.052 & 0.1645 & 0.0078 & 0.31 & $\mathrm{Y}$ & 2 & 2 & \\
\hline X0039 & 45 & 0.052 & 0.1667 & 0.0073 & 0.29 & Y & 2 & 2 & \\
\hline X0042 & 90 & 0.052 & 0.1633 & 0.0066 & 0.28 & $\mathrm{Y}$ & 3 & 3 & $\begin{array}{l}\text { This sample is difficult } \\
\text { to rate from the } \\
\text { photographs. There is } \\
\text { evidence of a bond line } \\
\text { throughout the sample. } \\
\text { The scratch does not } \\
\text { appear worse than the } \\
\text { rest of the sample. }\end{array}$ \\
\hline$\times 0047$ & 0 & 0.053 & 0.1655 & 0.0084 & 0.32 & Y & 2 & 2 & \\
\hline
\end{tabular}

* bond rating determined at 0.02 inches from root of weld. + bond rating determined at center of weld. 


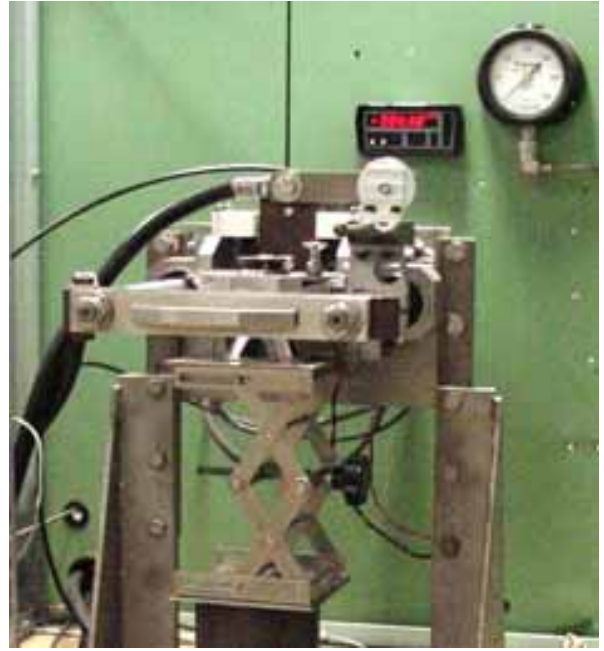

(a)

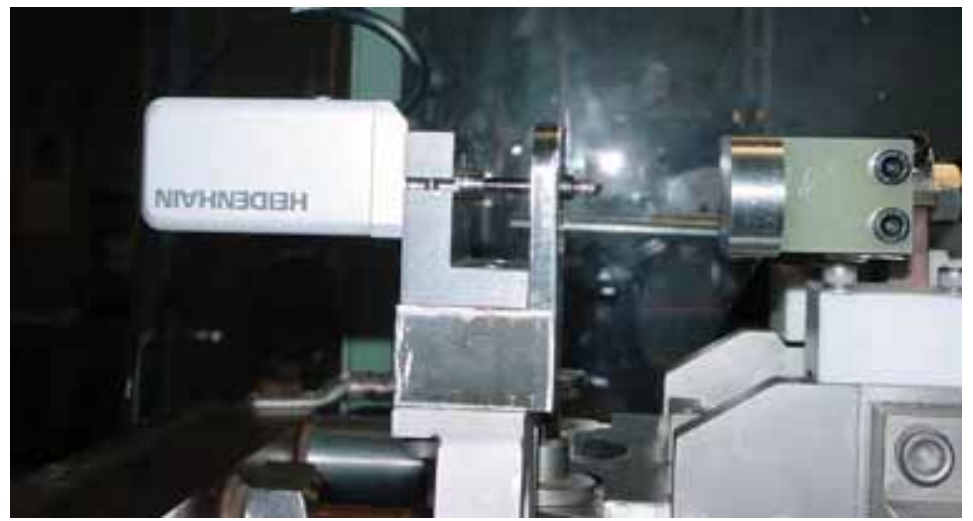

(b)

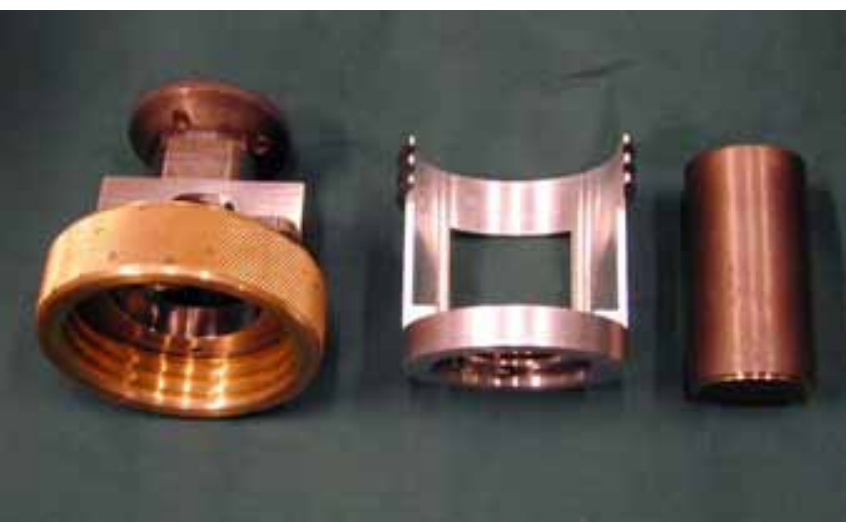

(c)

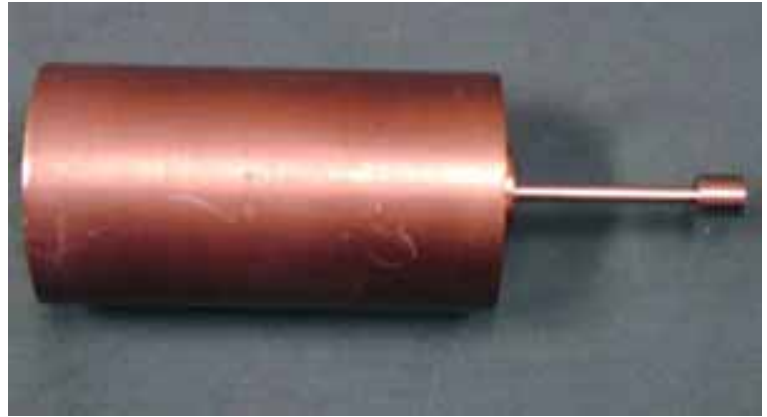

(d)

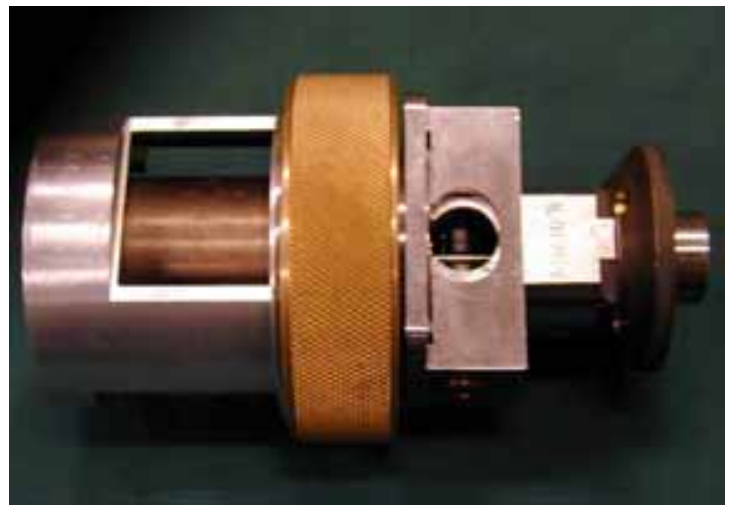

Figure 1. Weld equipment used (a) Weld head (b) displacement sensor and placement (c) assembly for welding (d) simulated LF-7 mass (e) fully assembled fixture including confining dies, "reservoir" and basket.

(e) 


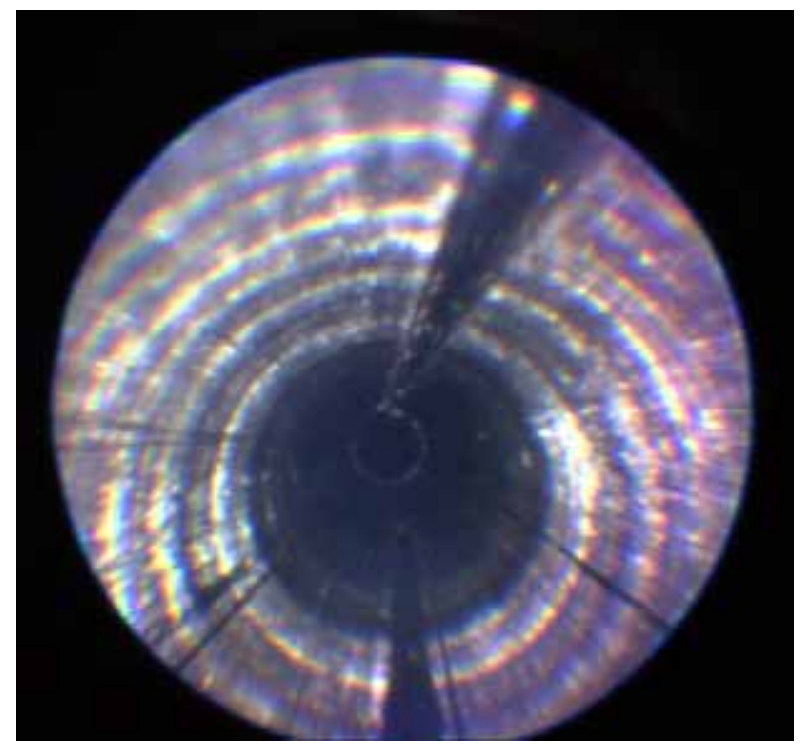

(a)

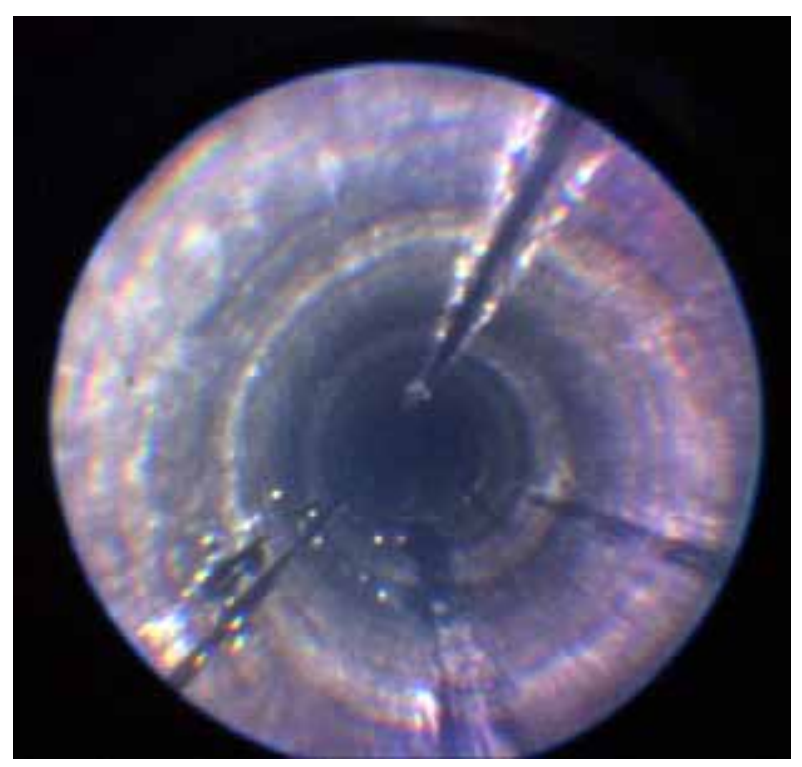

(c)

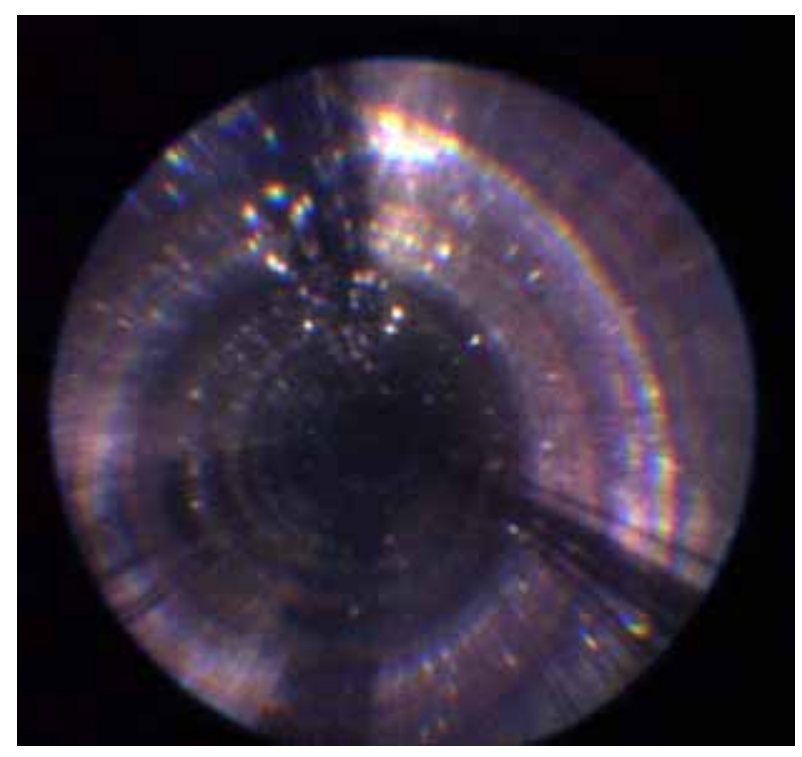

(b)

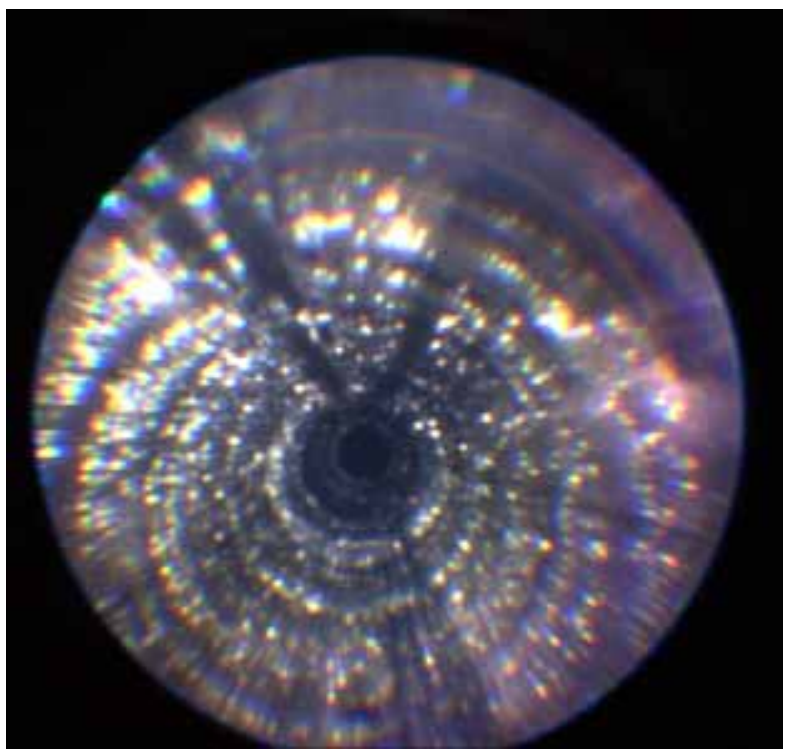

(d)

Figure 2. Forward looking borescope images (a) X0034 (b) X0039 (c) X0042 and (d) X0047 


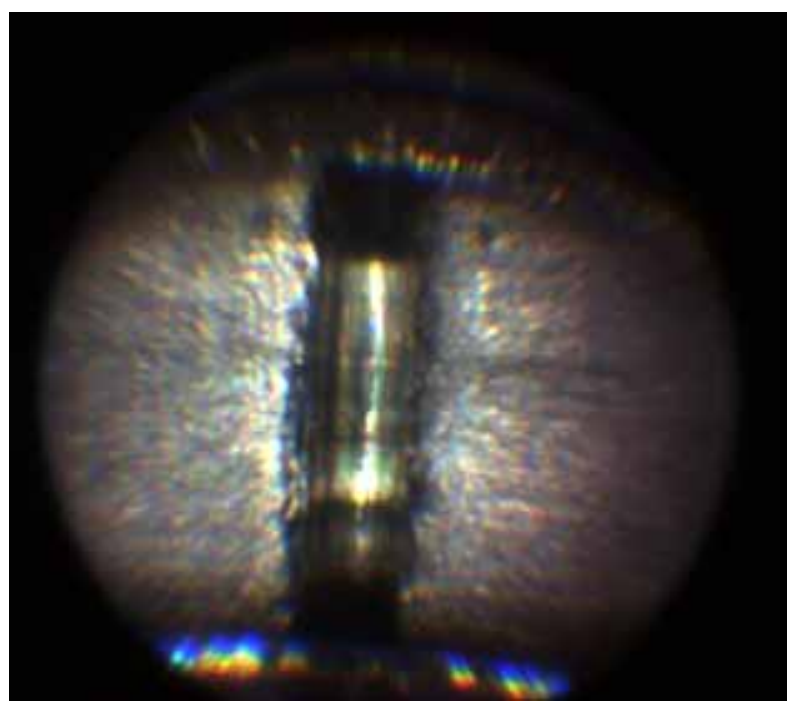

(a)

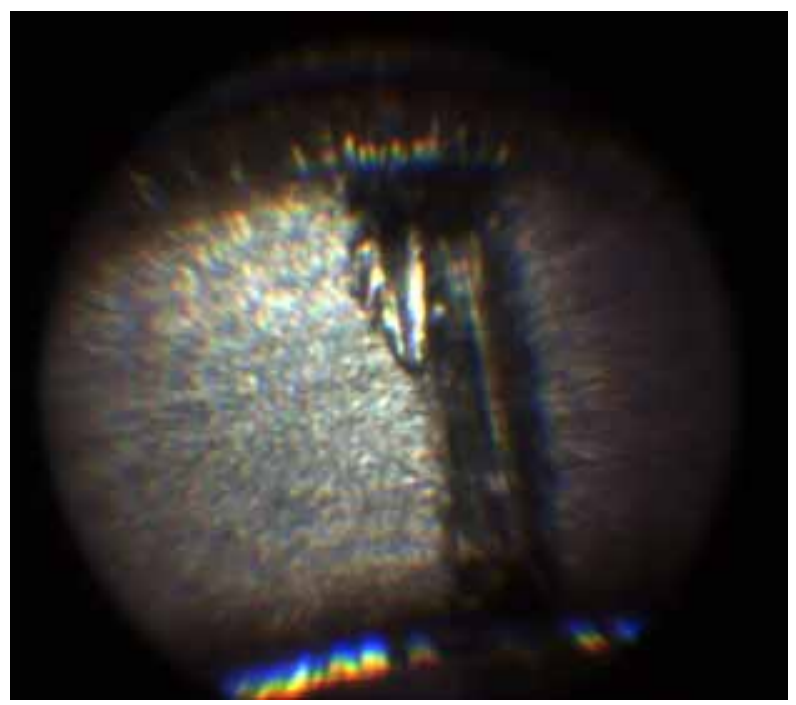

(c)

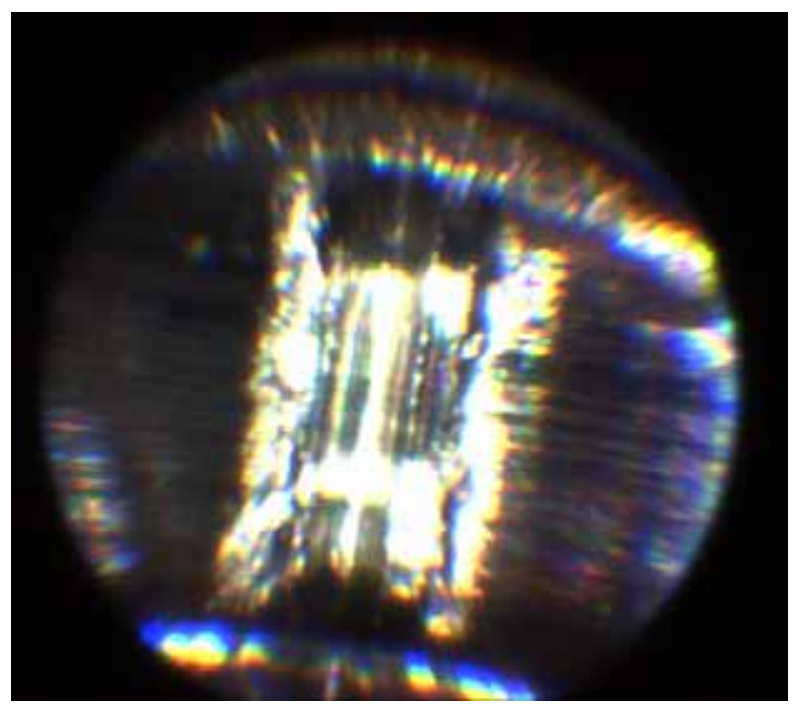

(b)

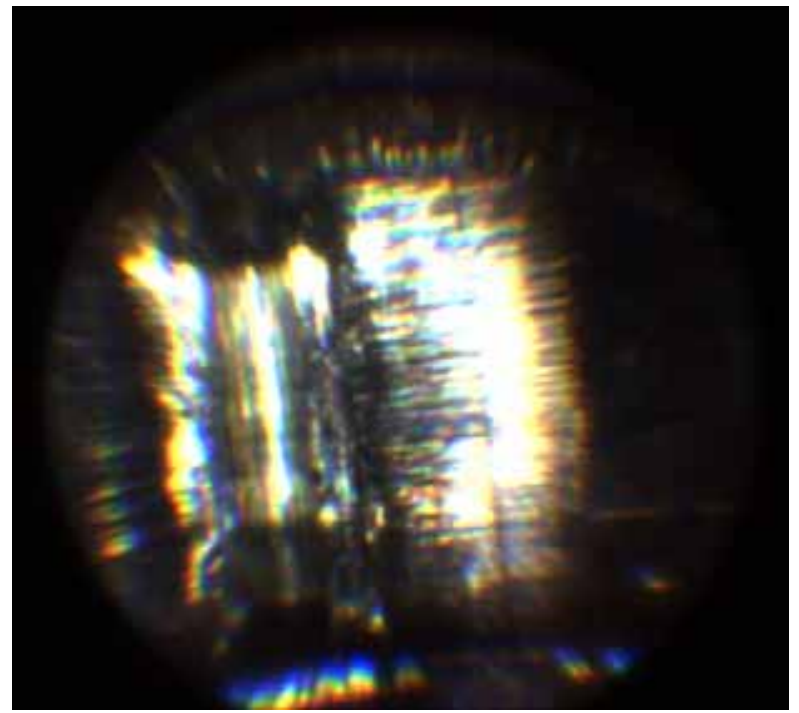

(d)

Figure 3. Side looking borescope images (a) X0034 (b) X0039 (c) X0042 and (d) X0047 


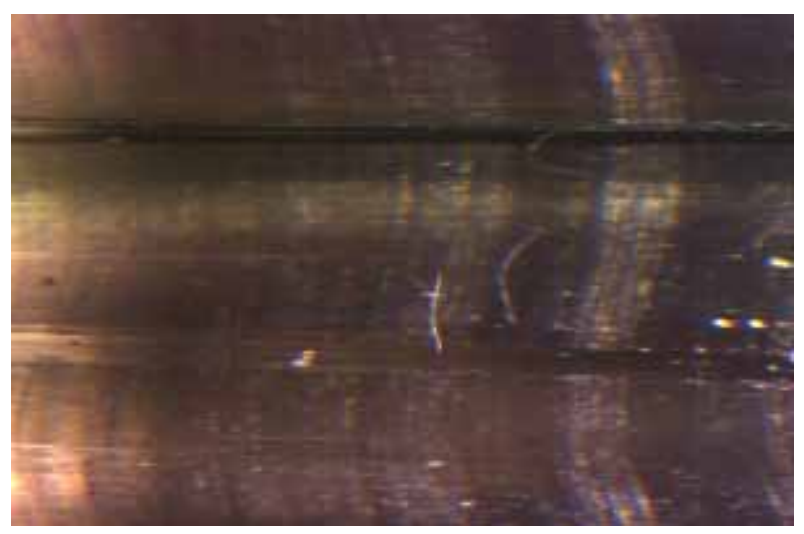

(a)

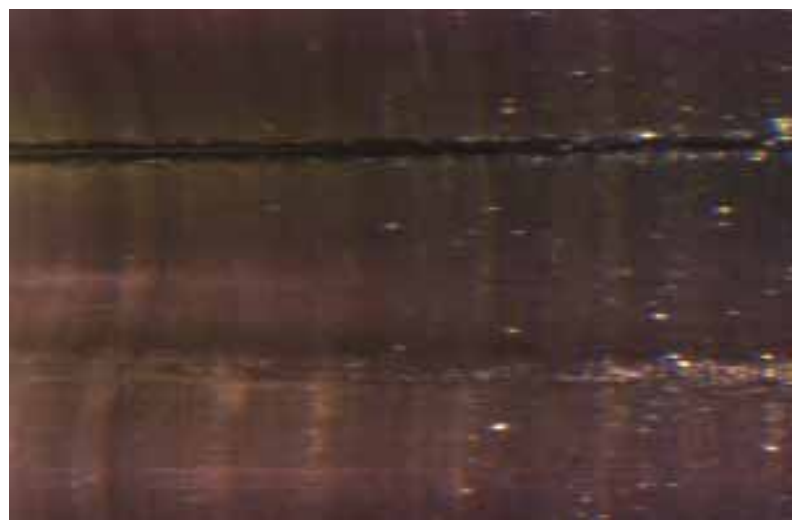

(c)

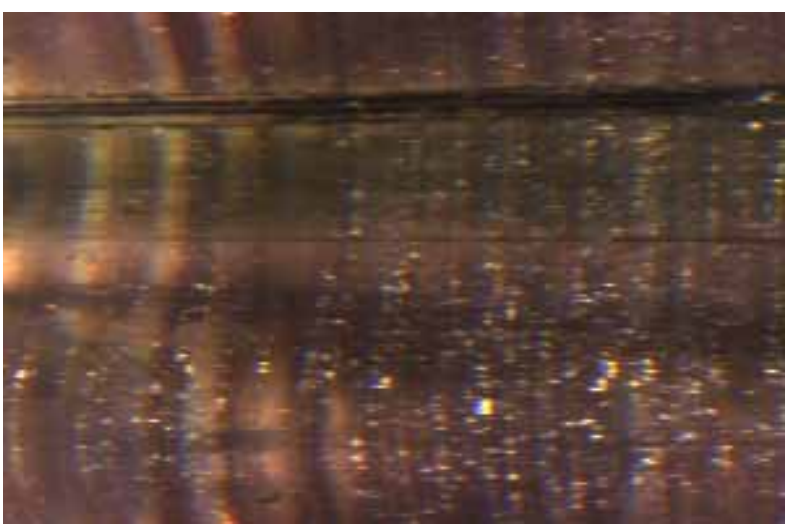

(b)

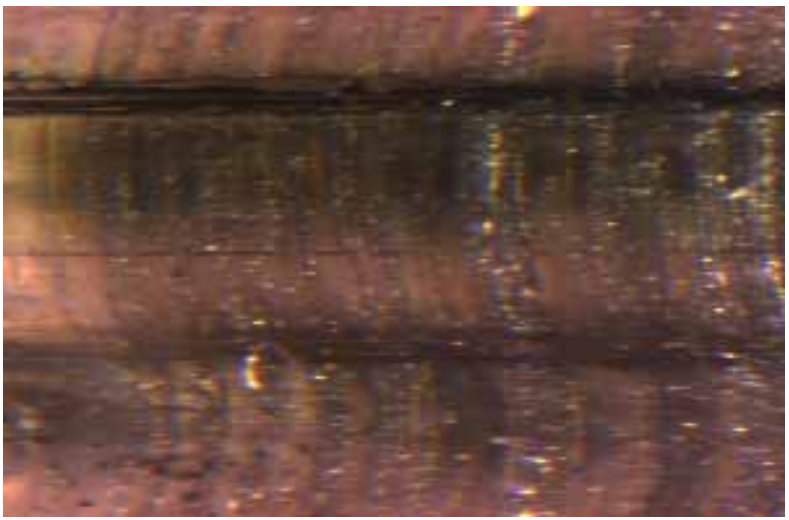

(d)

Figure 4. Unwrapped images using the True Color Tube Borescope Inspection System (TCTBIS) for (a) X0034 (b) X0039 (c) X0042 and (d) X0047. 


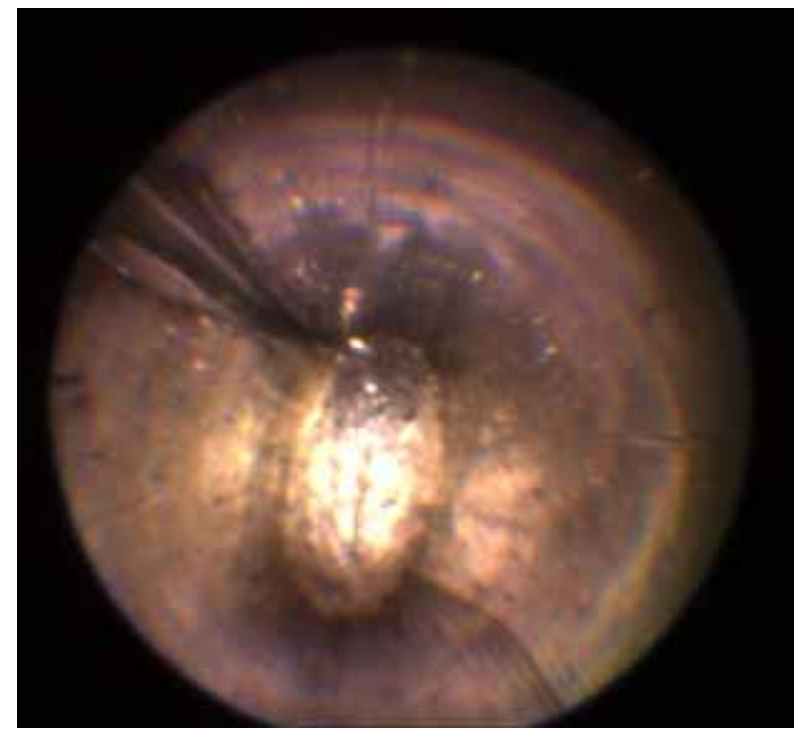

(a)

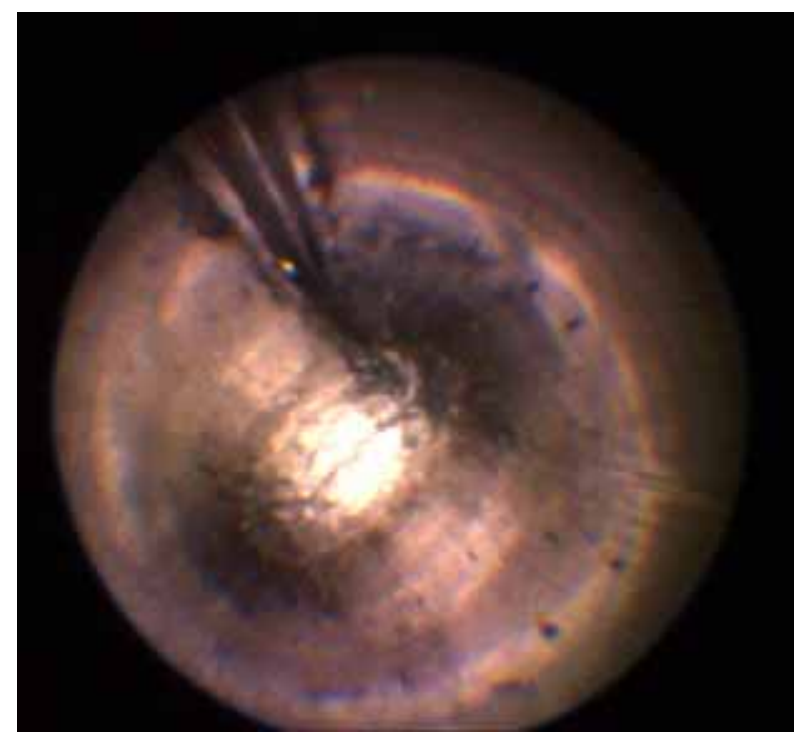

(c)

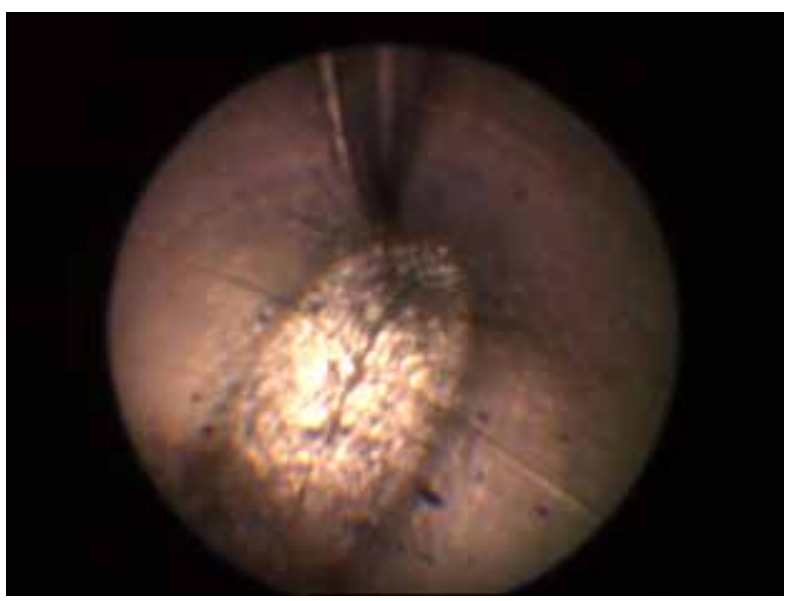

(b)

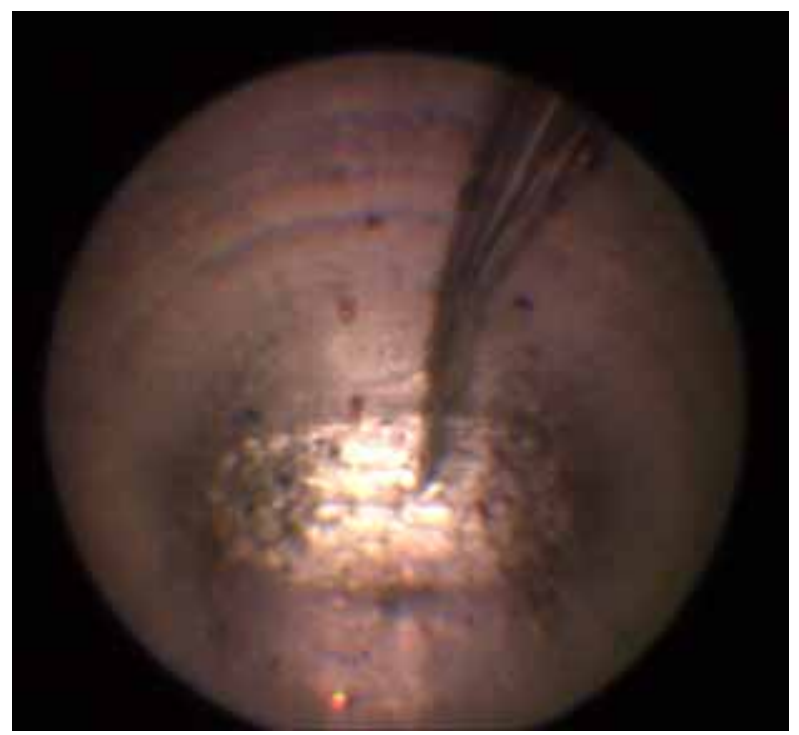

(d)

Figure 5. Forward looking borescope image after welding of (a) X0047 $0^{\circ}$ (b) X0034 $45^{\circ}$ (c) X0039 $45^{\circ}$ and (d) $\mathrm{X0042} \mathbf{9 0}^{\circ}$. Note target values are reported, not actual. 


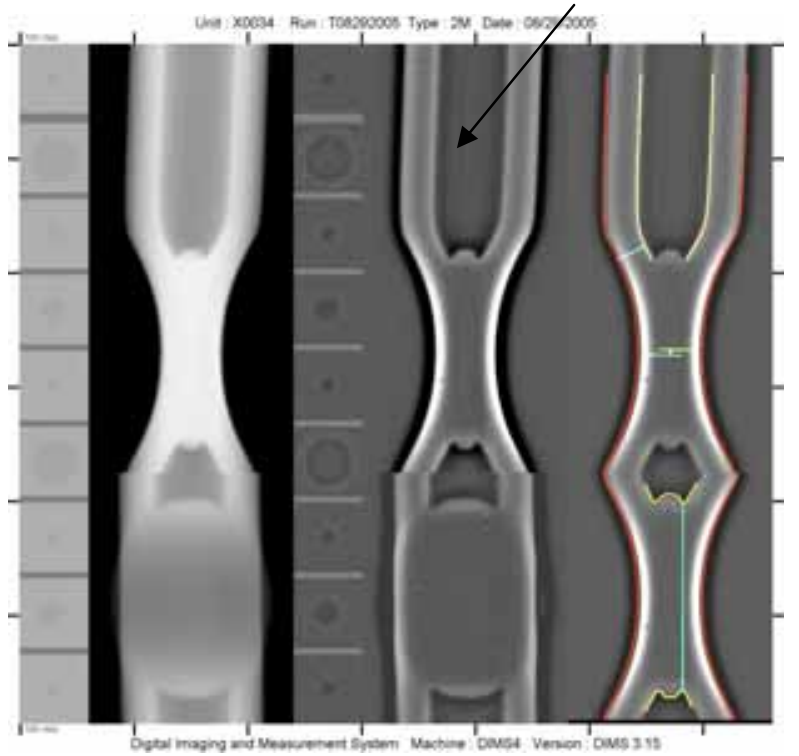

(a) $\mathrm{X} 0034$

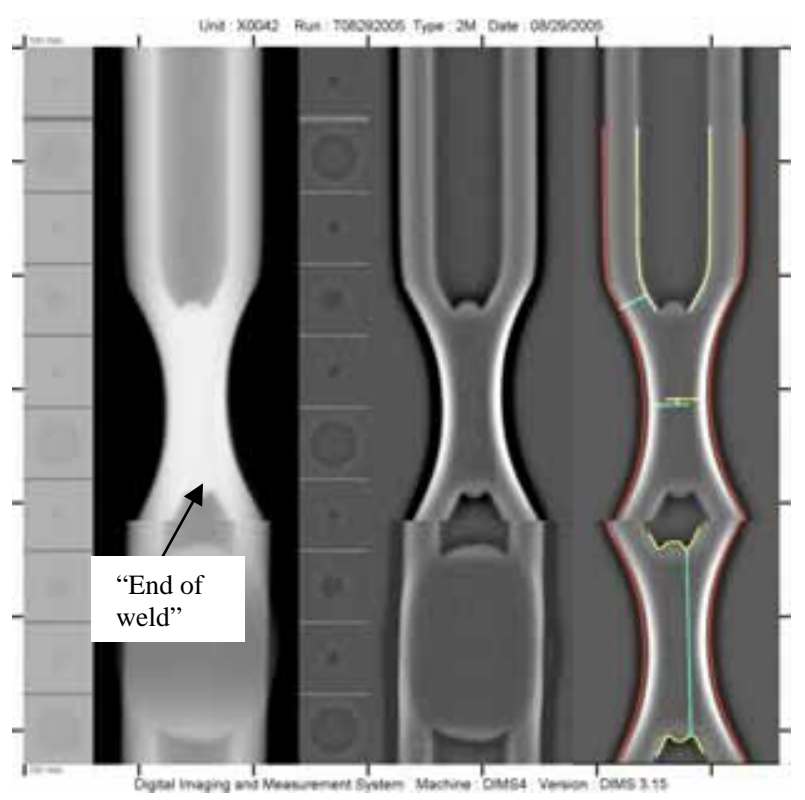

(c) X0042

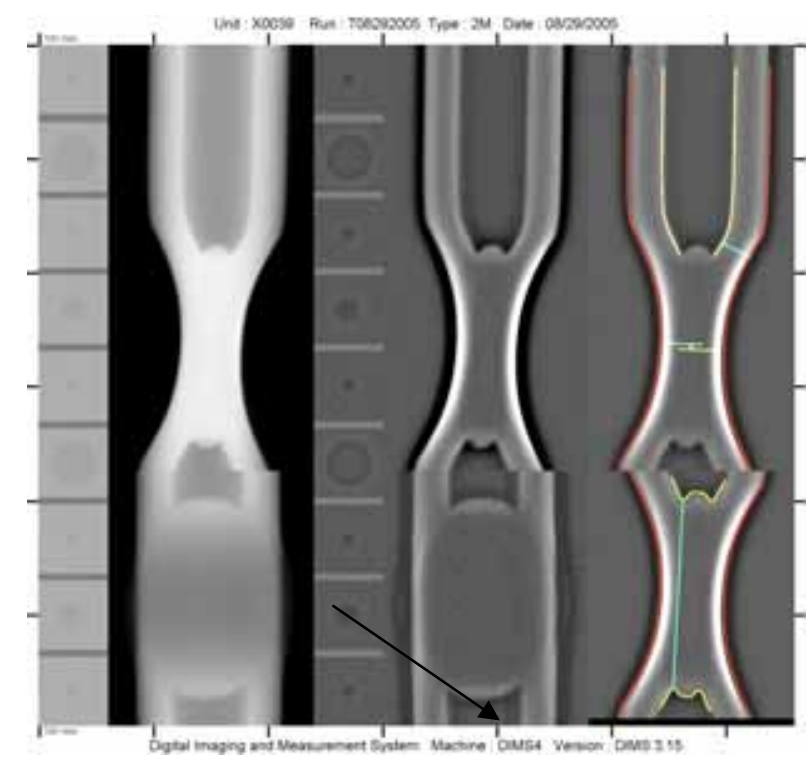

(b) X0039

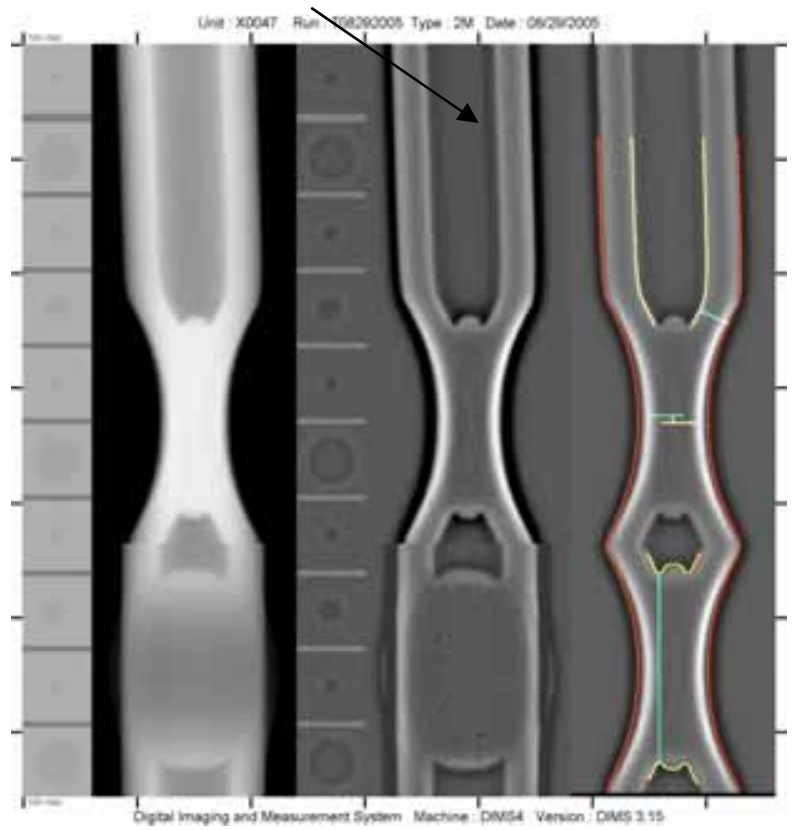

(d) X0047

Figure 6. Face and side view radiographs of scratched and welded stems (a) X0034 (b) X0039 (c) X0042 (d) X0047. Note the presence of fiduciary marks in image on lower right side of all these images. These are used to determine closure length, wall thickness, alignment, etc. 


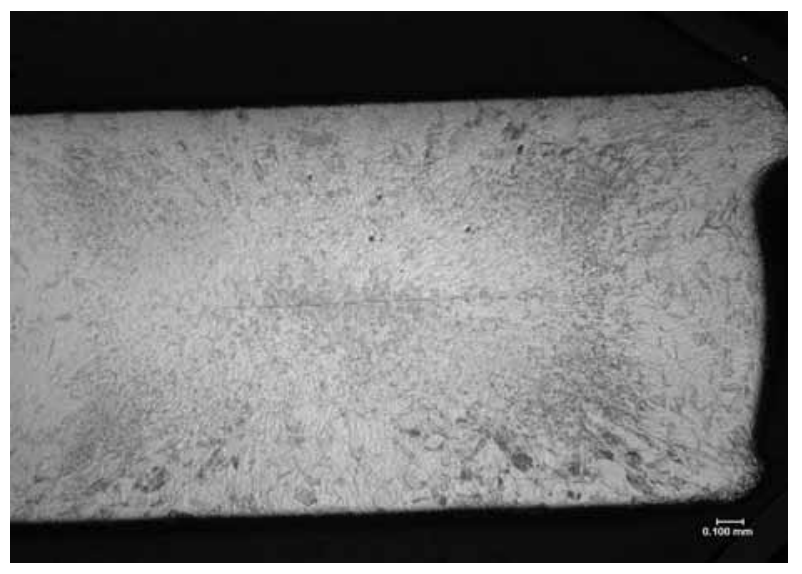

(a)

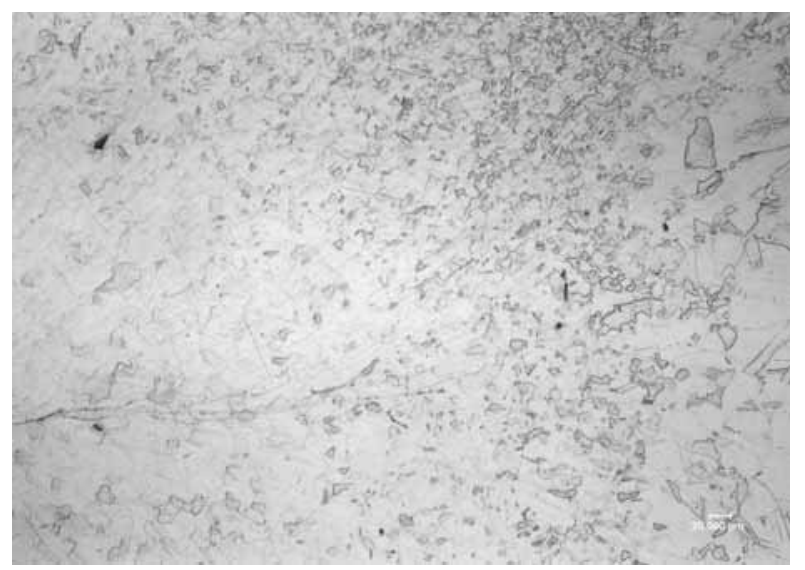

(c)

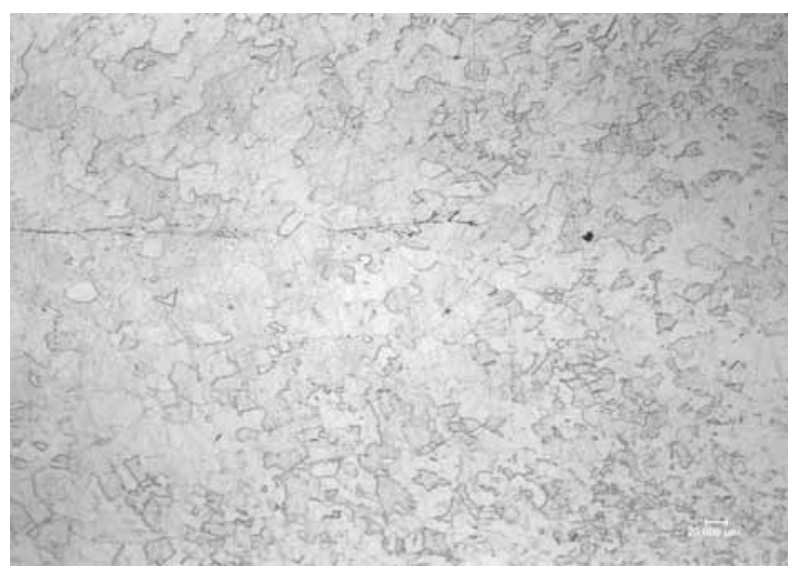

(e)

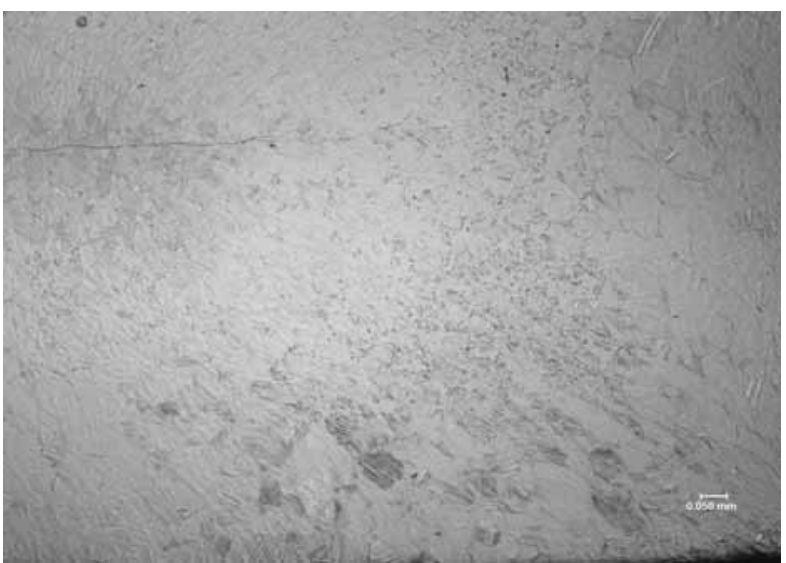

(b)

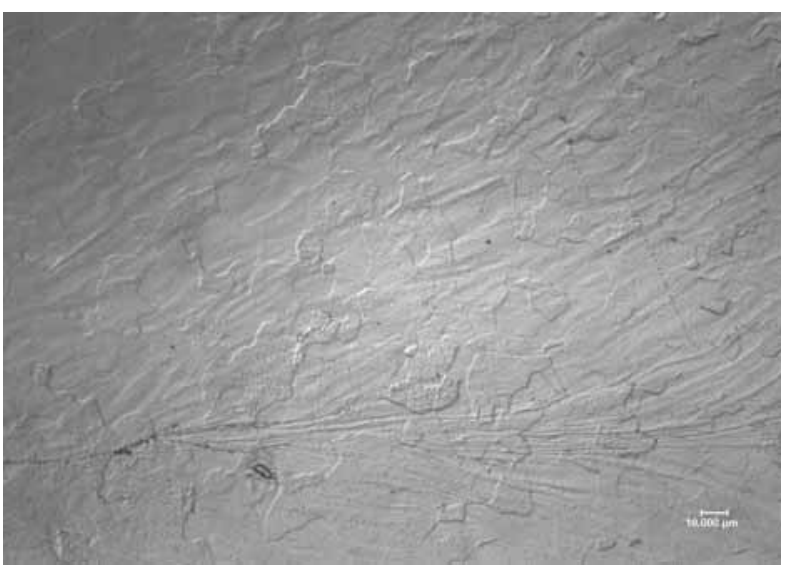

(d)

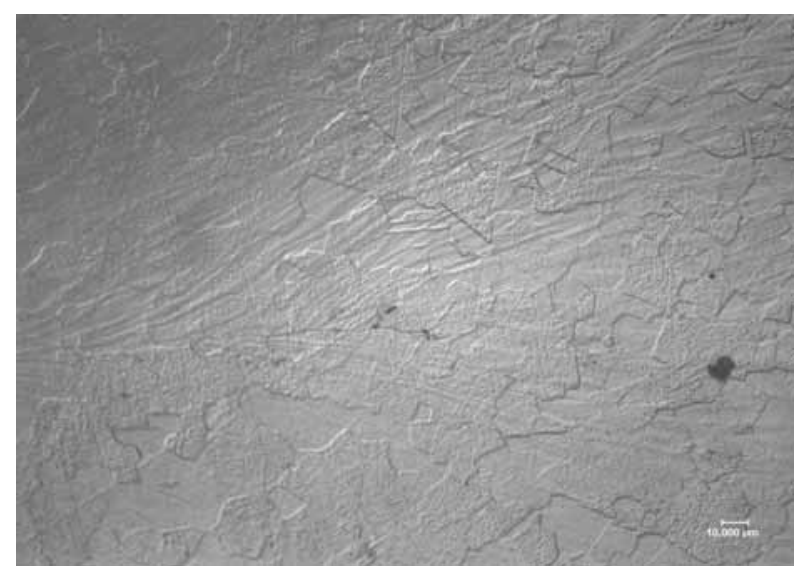

(f) 


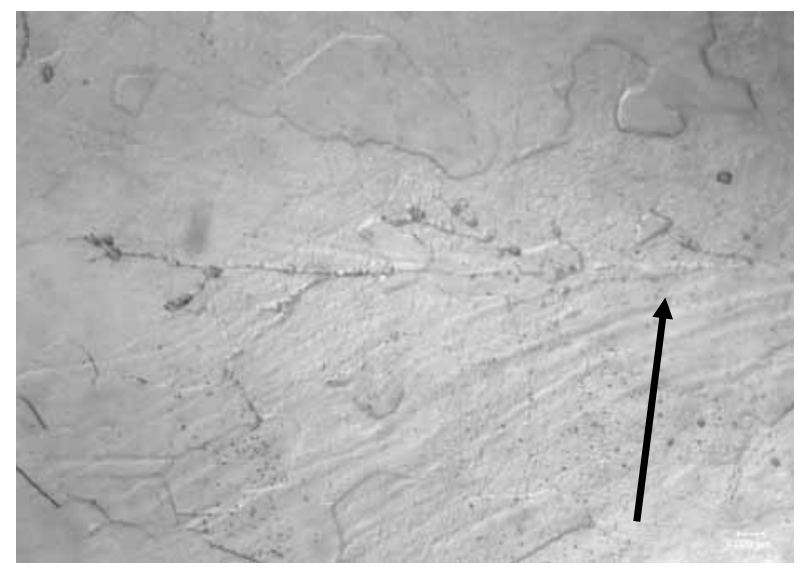

(g)

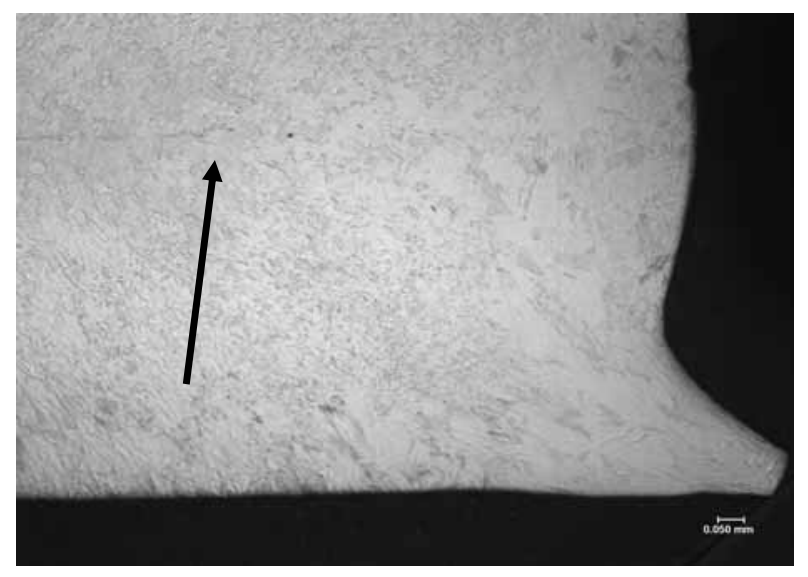

(i)

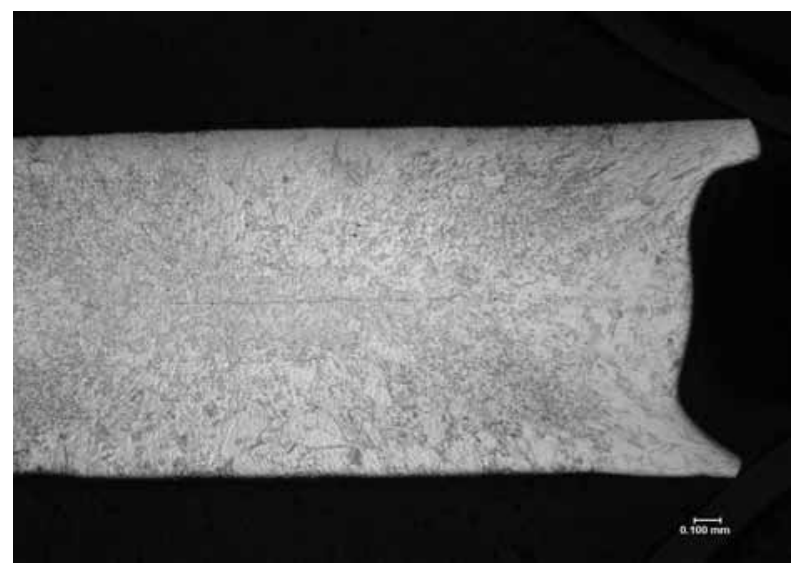

(h)

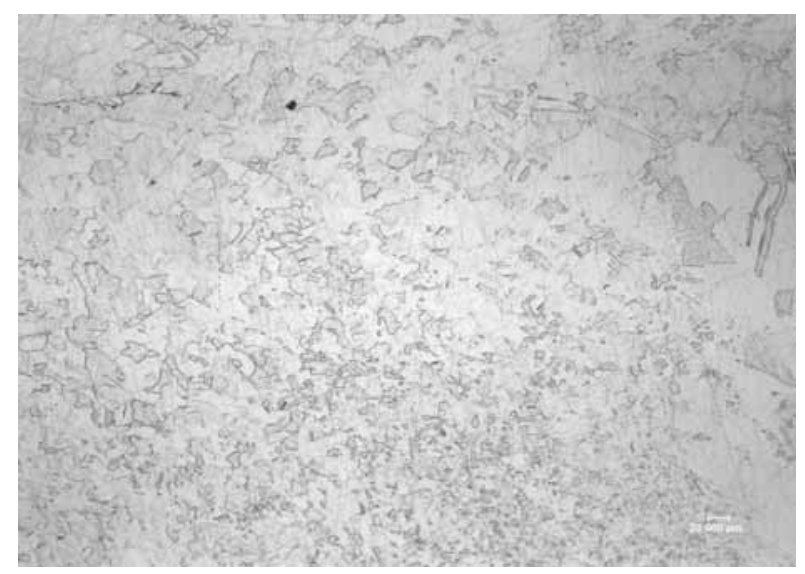

(j) 


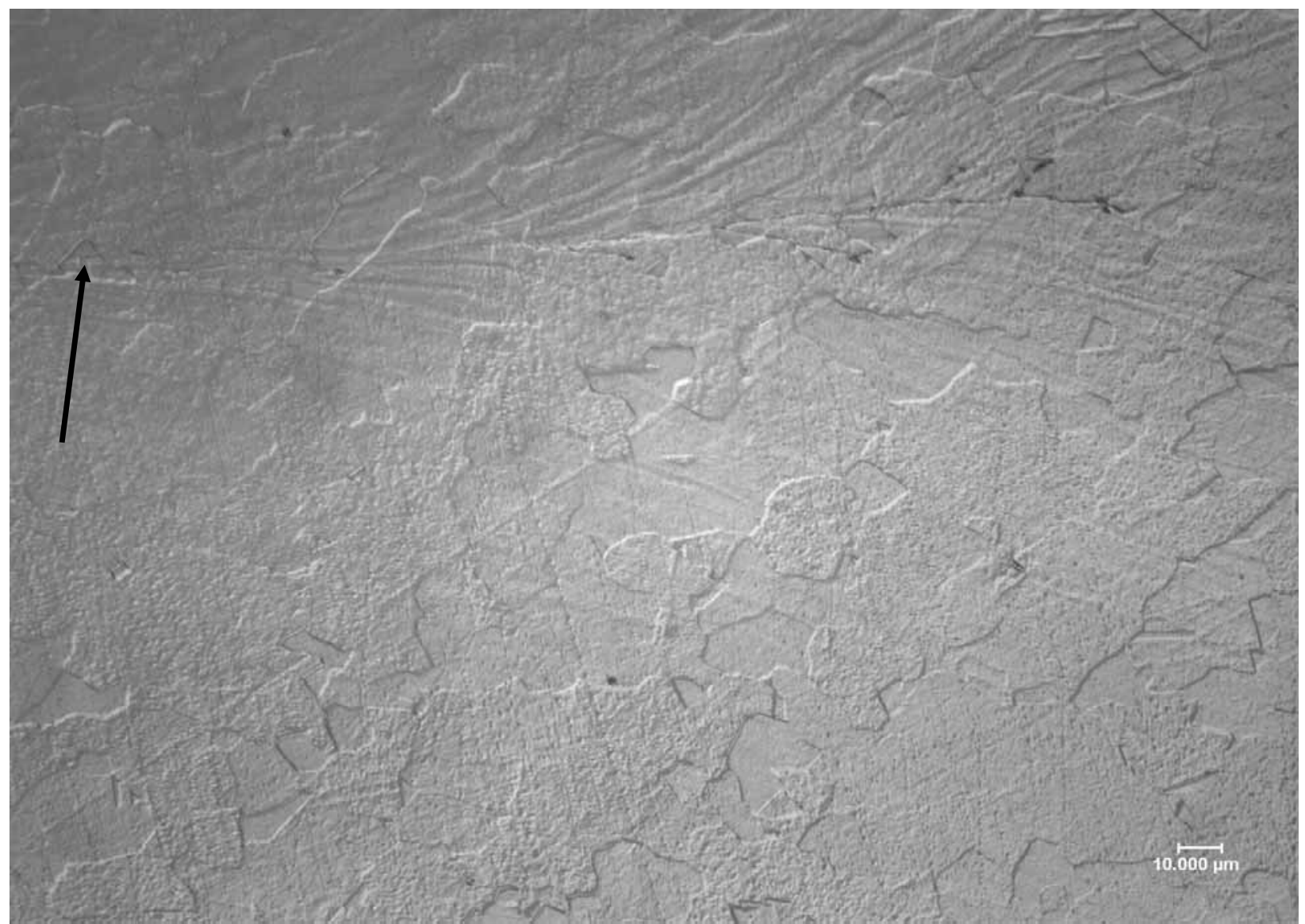

$(\mathrm{k})$

Figure 7. Transverse cross sections in the crow's foot of weld in stem X0034 at (a) 50X (b) 100X (c) 200X and (d) $500 \mathrm{X}$ magnifications, scratch at $45^{\circ}$ from axis, at 0.02 " from end of weld, (e) $200 \mathrm{X}$, (f) $500 \mathrm{X}$ and (g) $1000 \mathrm{X}$ at a distance about 0.06 from end of weld, (h) $50 \mathrm{X}$ (i) $100 \mathrm{X}$ and (j) $200 \mathrm{X}$ and (k) $500 \mathrm{X}$ at the weld center. See Figure 5 for nominal end of weld and note that the bond line does not exhibit any gross disruption, however, there is evidence of the prior scratch in two of the three axial locations as indicated by the arrows. 


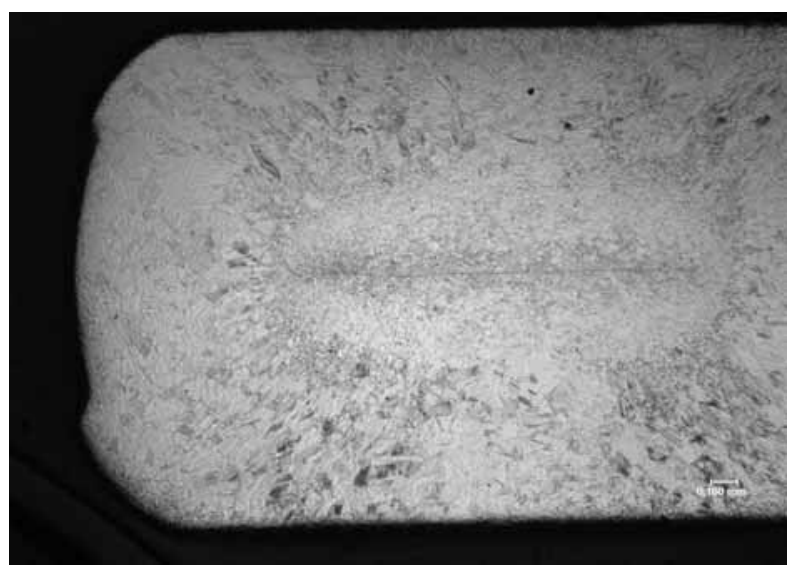

(a)

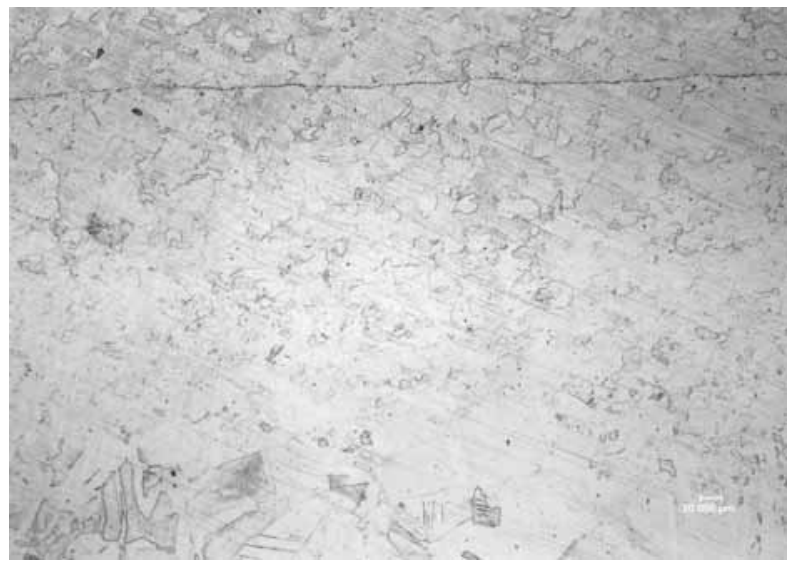

(c)

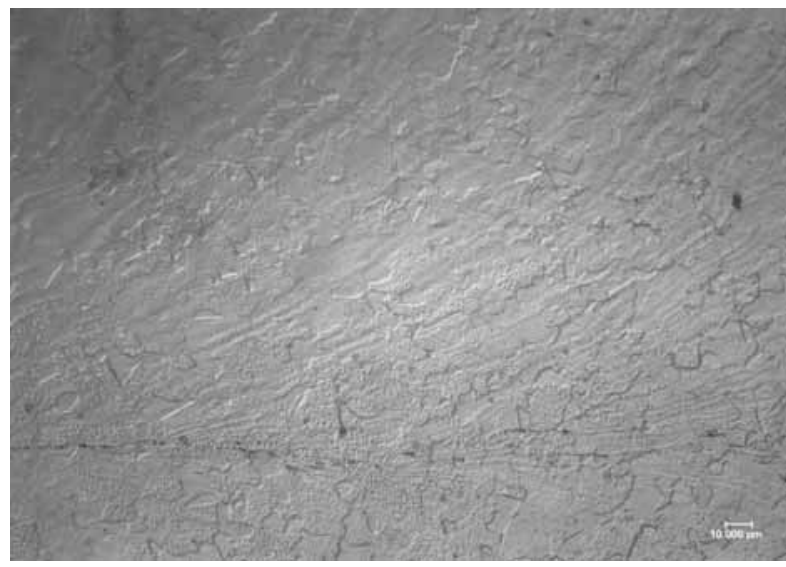

(e)

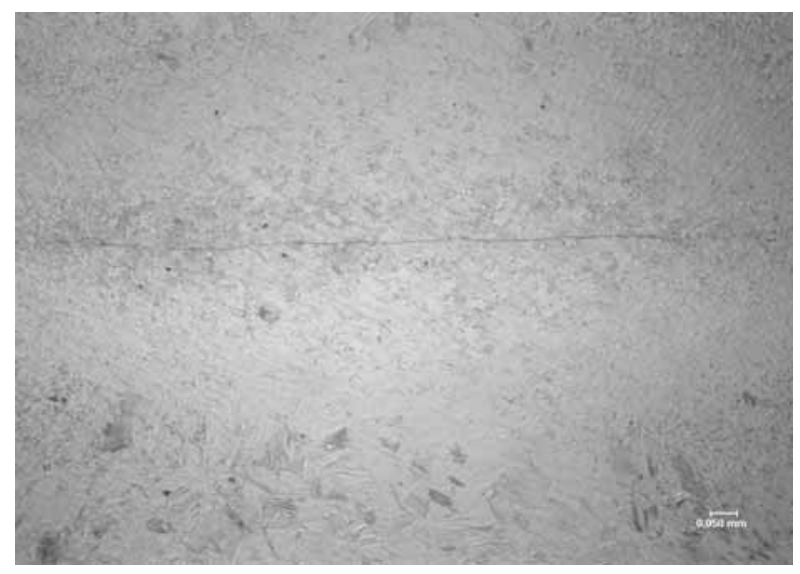

(b)

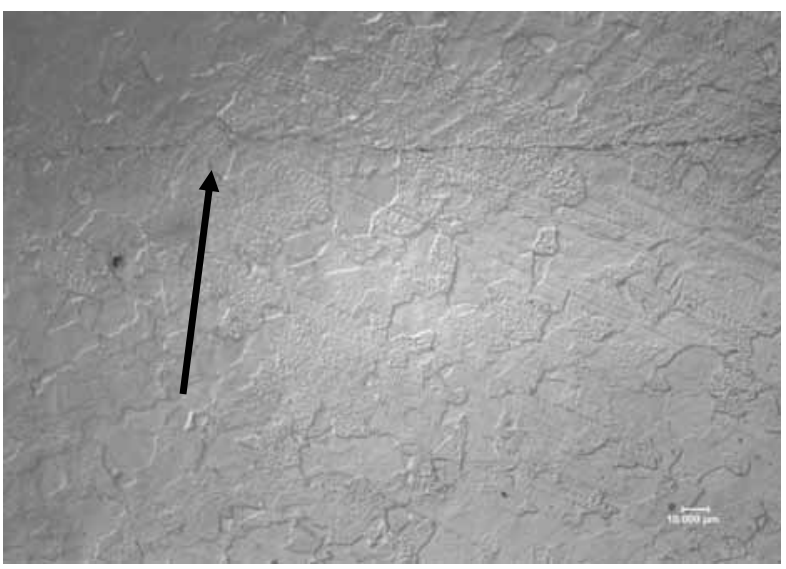

(d)

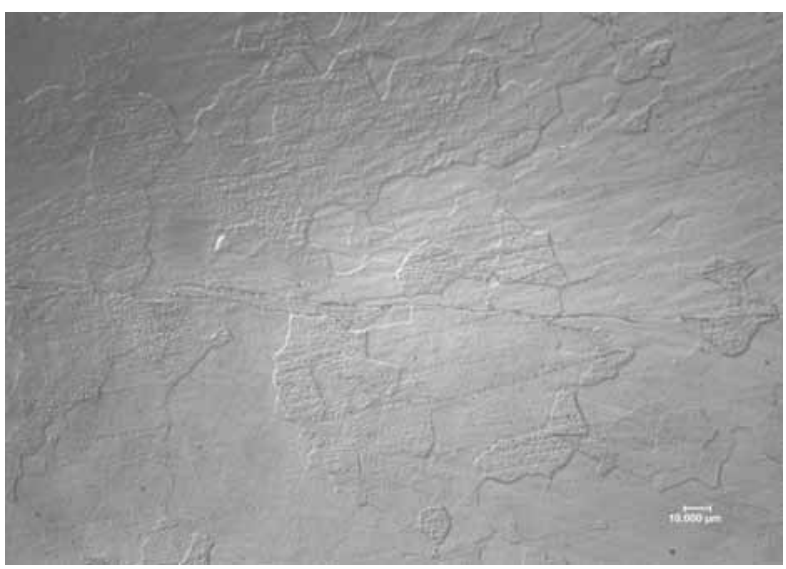

(f) 


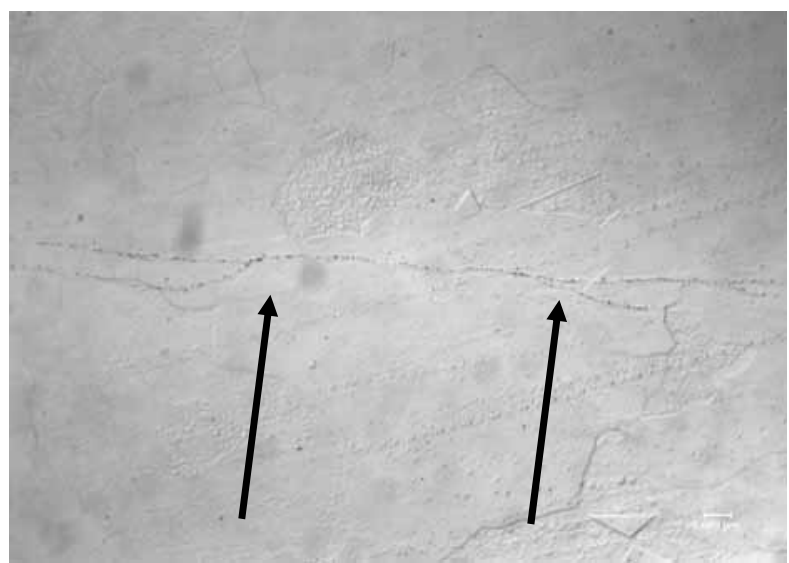

(g)

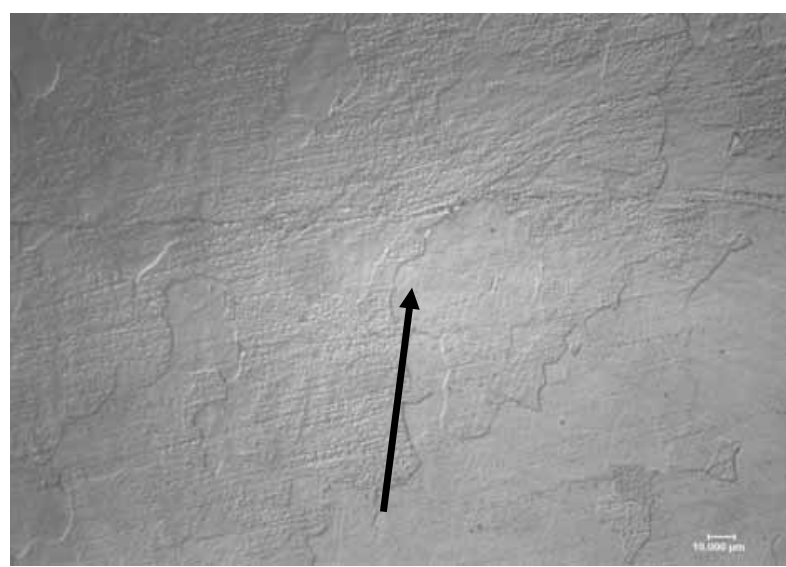

(i)

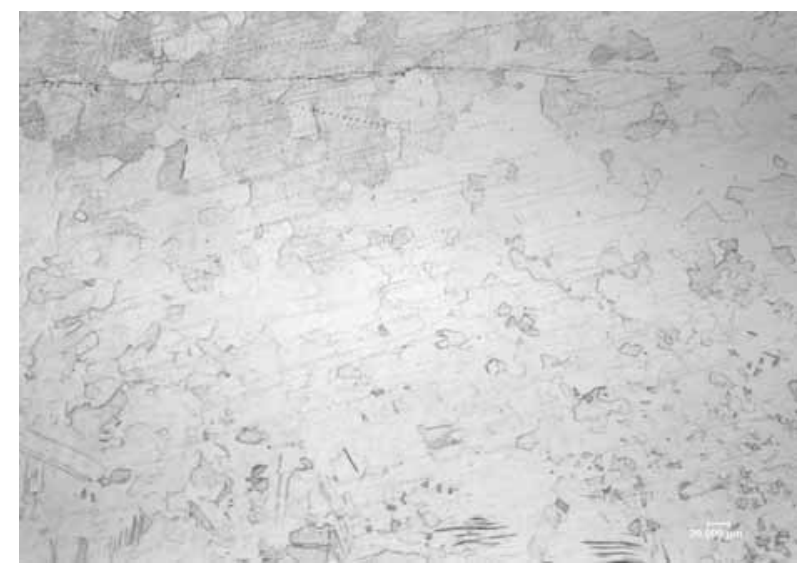

(h)

Figure 8. Transverse cross sections of welds at magnifications of (a) $50 \mathrm{X}$ (b) $100 \mathrm{X}$ (c) $200 \mathrm{X}$ (d) $500 \mathrm{X}$ (e) $500 \mathrm{X}$ at 0.02 inch from end of weld and at (f) $500 \mathrm{X}$ and (g) $1000 \mathrm{X}$ at 0.06 from end of weld and at (h) $200 \mathrm{X}$ and (i) $500 \mathrm{X}$ at the center of the weld of sample X0039. The arrow in (d) highlights nonlinear indication attributed to scratch. 


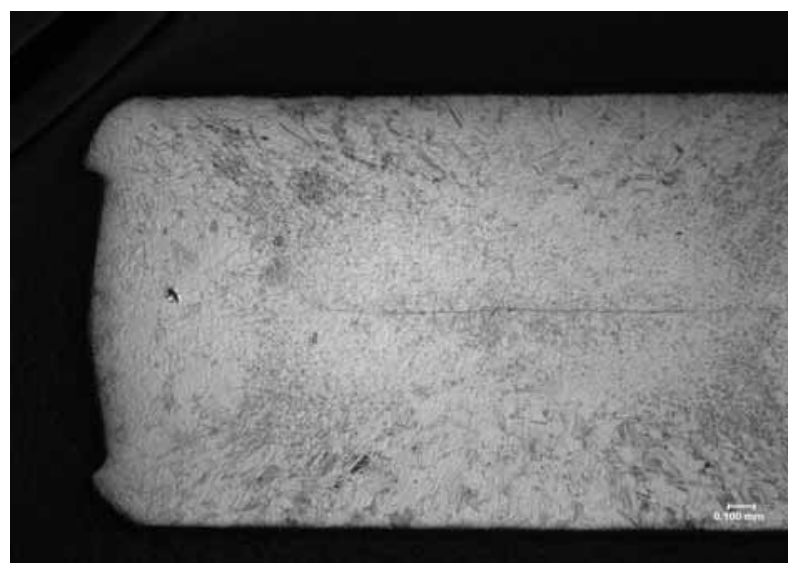

(a)

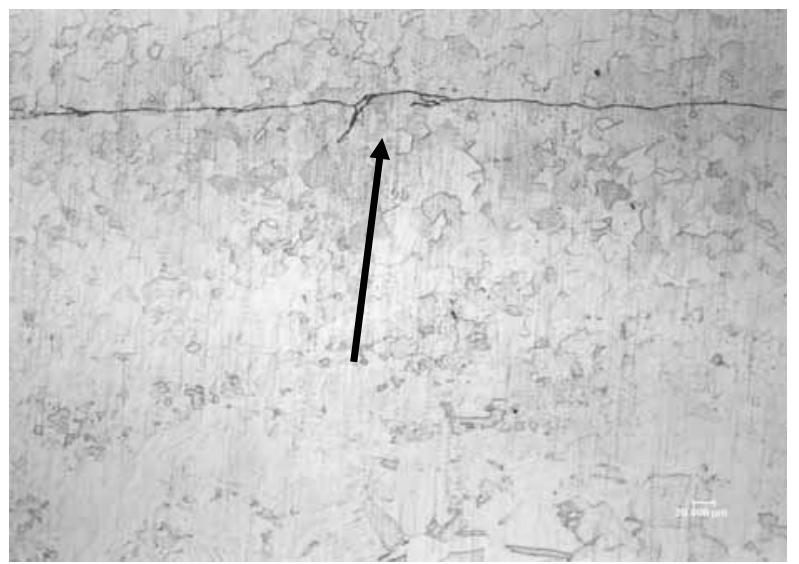

(c)

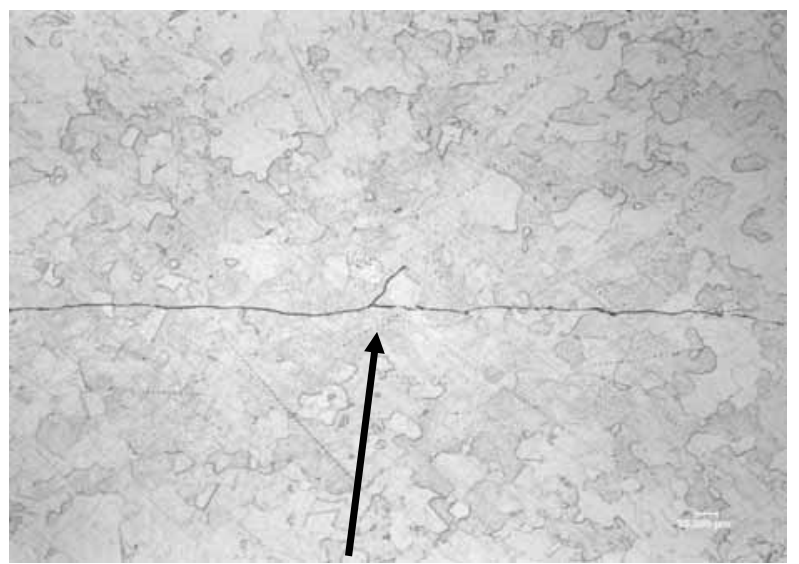

(e)

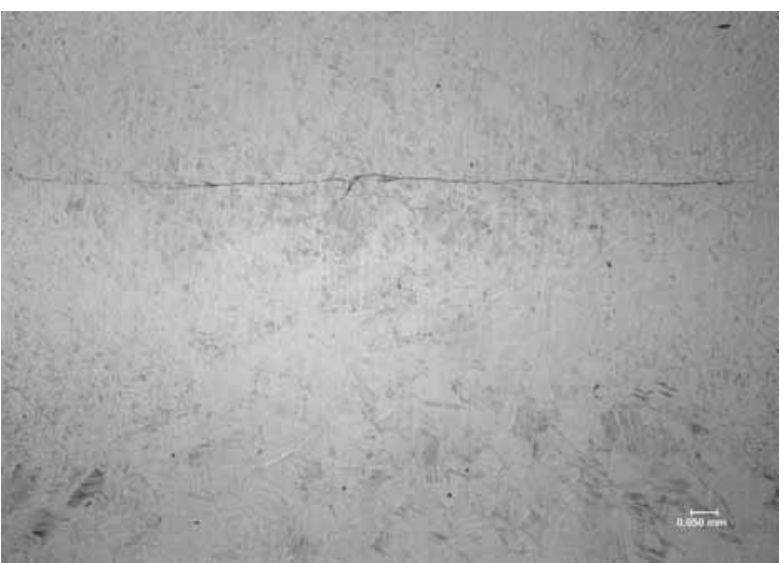

(b)

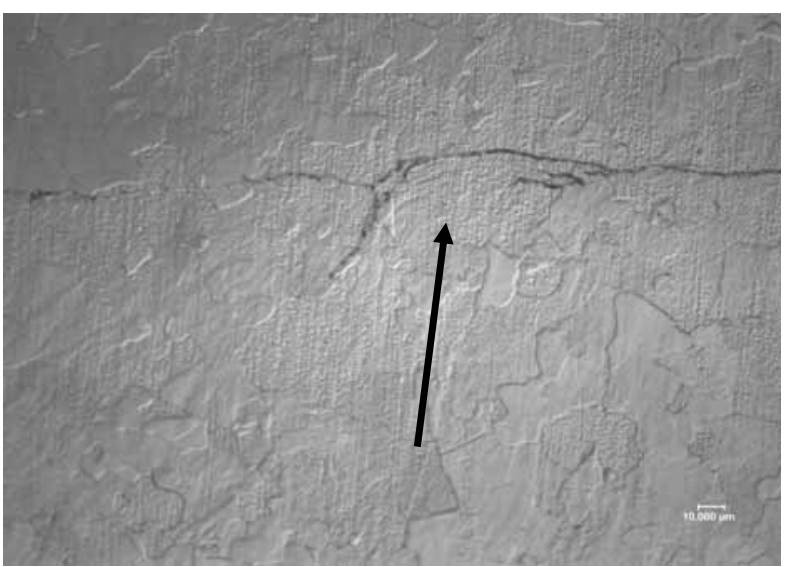

(d)

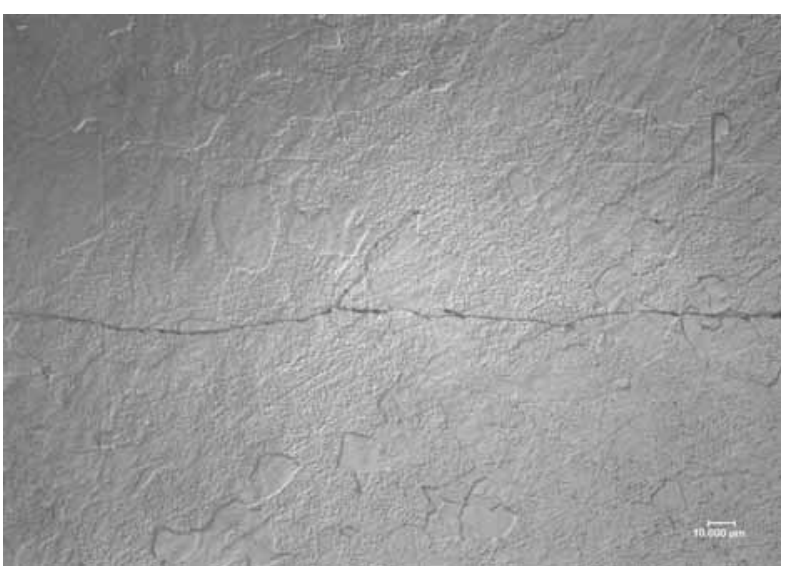

(f) 


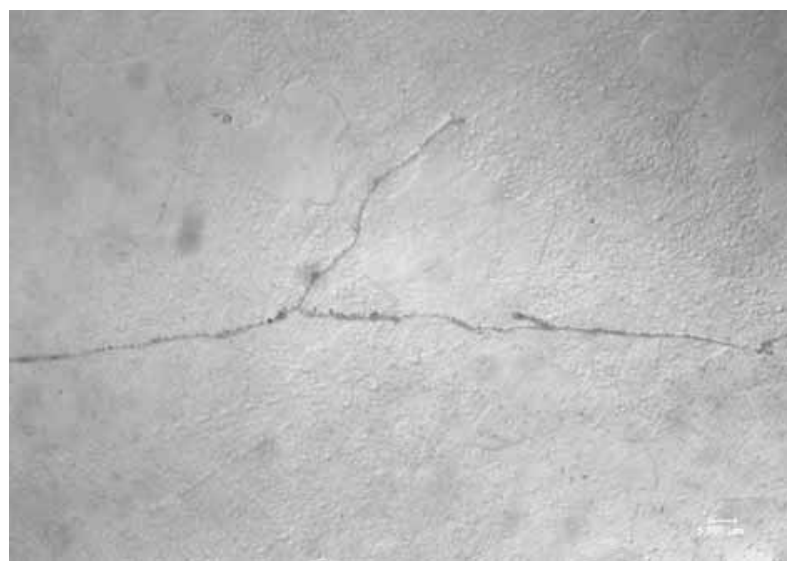

(g)

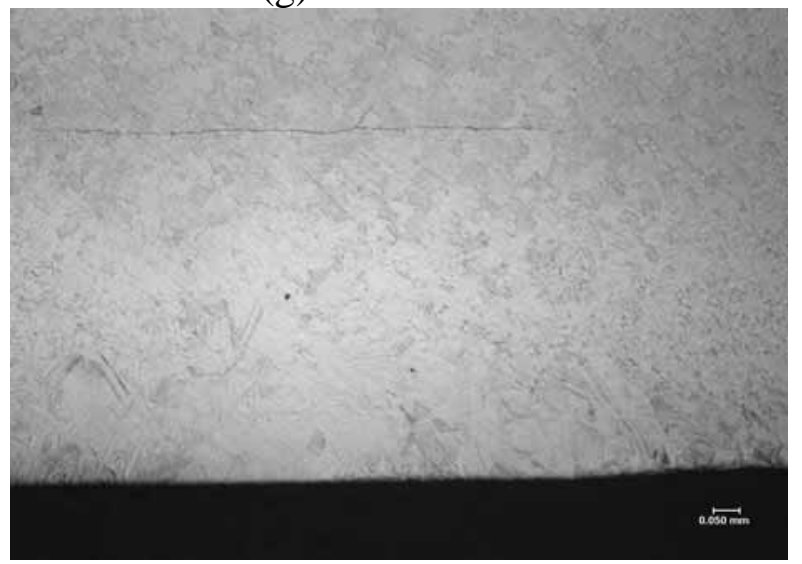

(i)

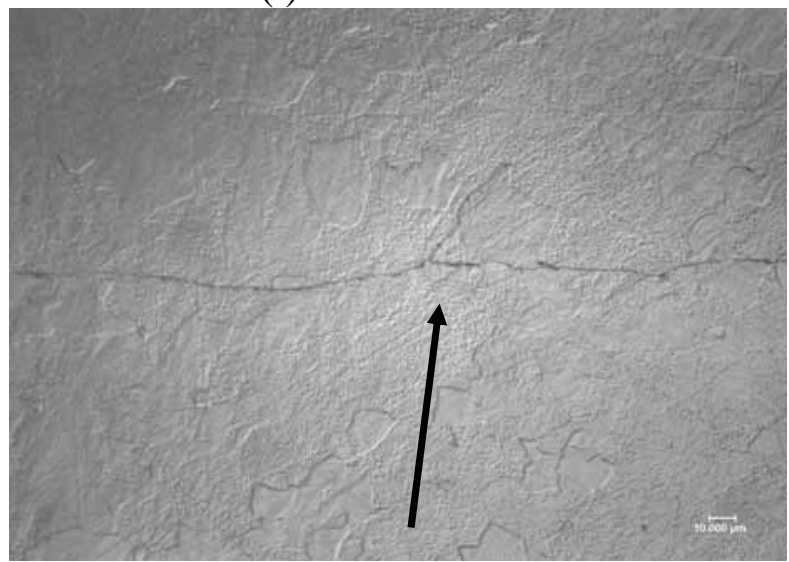

$(\mathrm{k})$

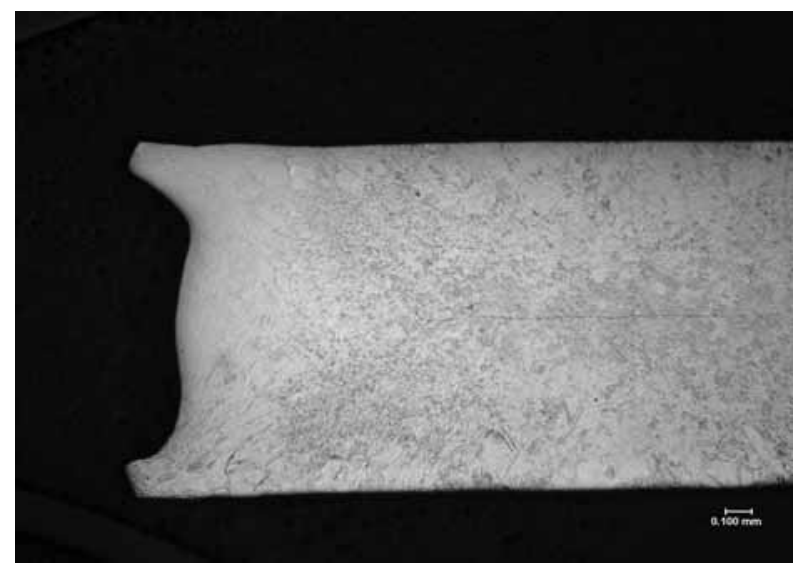

(h)

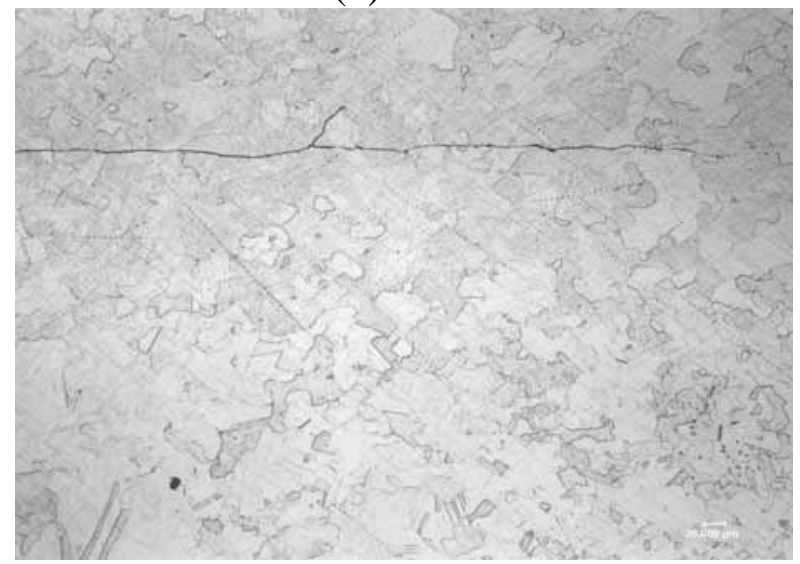

(j)

Figure 9. Transverse cross sections of welds at magnification of (a) $50 \mathrm{X}$ (b) $100 \mathrm{X}$ (c) $200 \mathrm{X}$ and (d) $500 \mathrm{X}$ at 0.02 from end of weld and (e) $200 \mathrm{X}$ (f) $500 \mathrm{X}$ and (g) $1000 \mathrm{X}$ at 0.06 inch from the end of the weld and at (h) $50 \mathrm{X}(\mathrm{i}) 100 \mathrm{X}(\mathrm{j}) 200 \mathrm{X}$ and $(\mathrm{k}) 500 \mathrm{X}$ in the center of the weld for sample X0042. Note the there is a detectable disruption in the bond line in all three axial locations, as highlighted by arrows, however it does not appear to adversely affect the weld. 


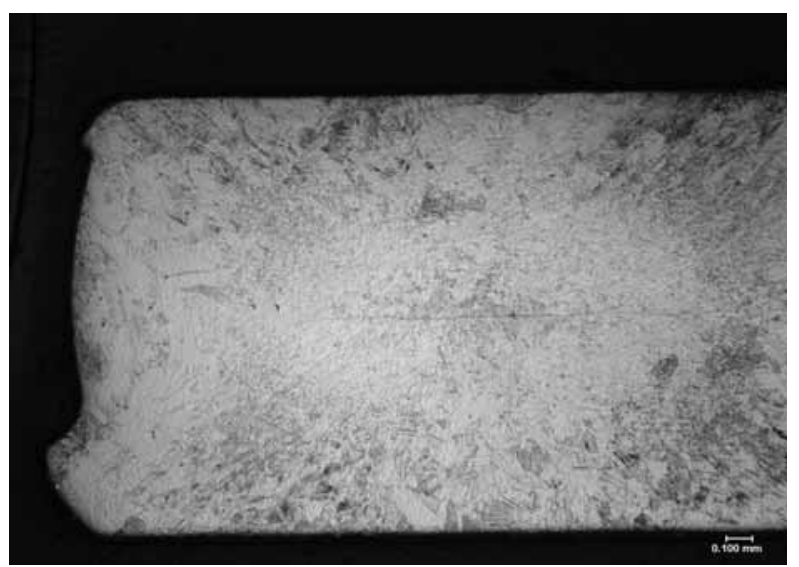

(a)

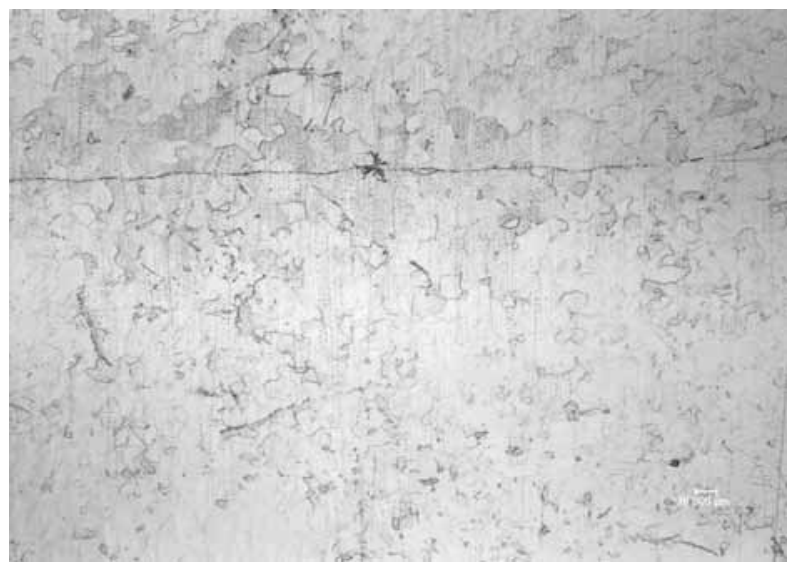

(c)

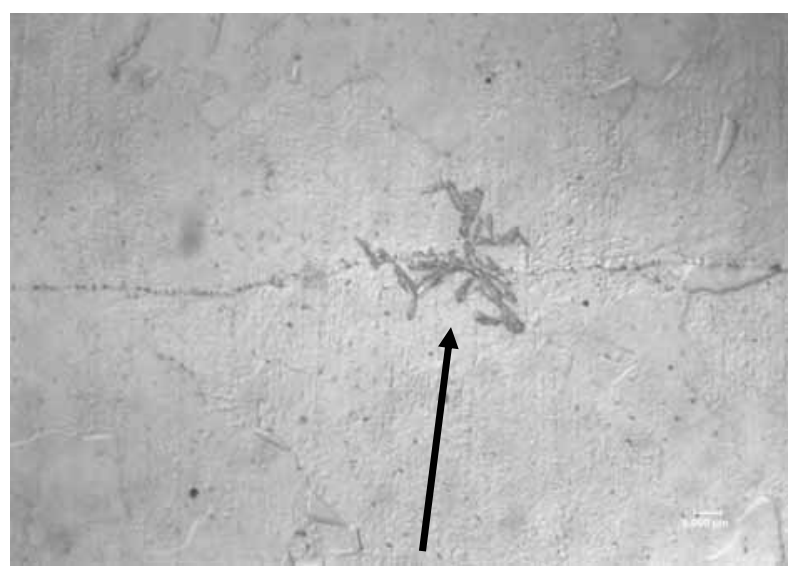

(e)

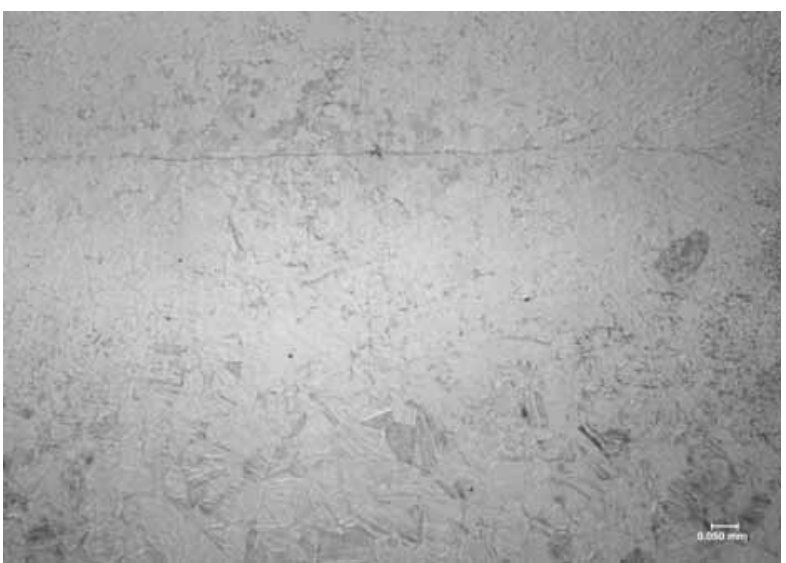

(b)

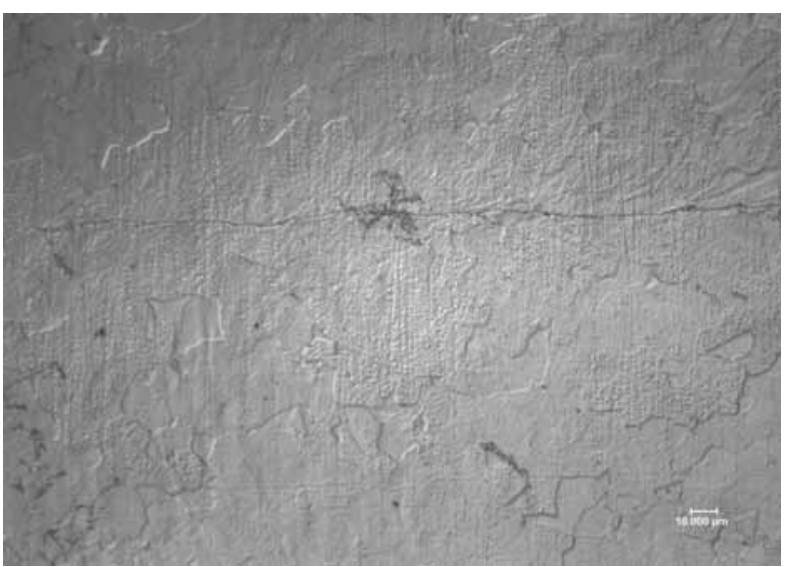

(d)

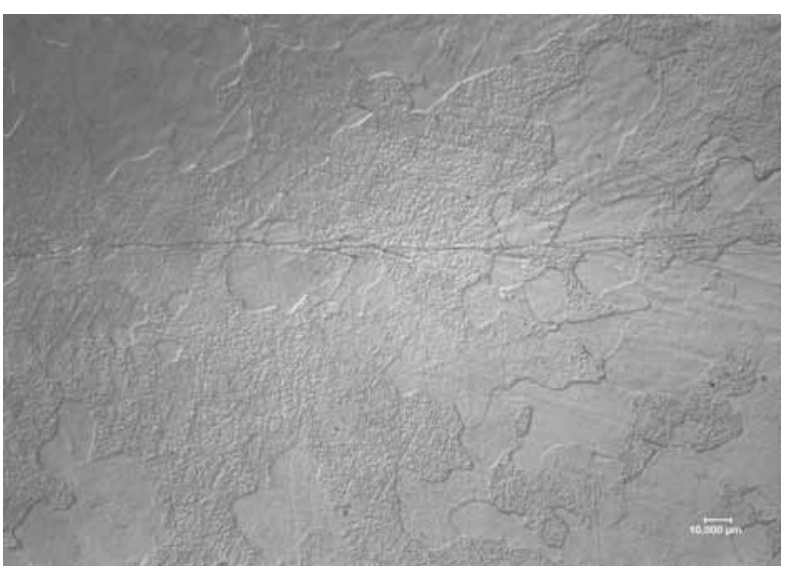

(f) 


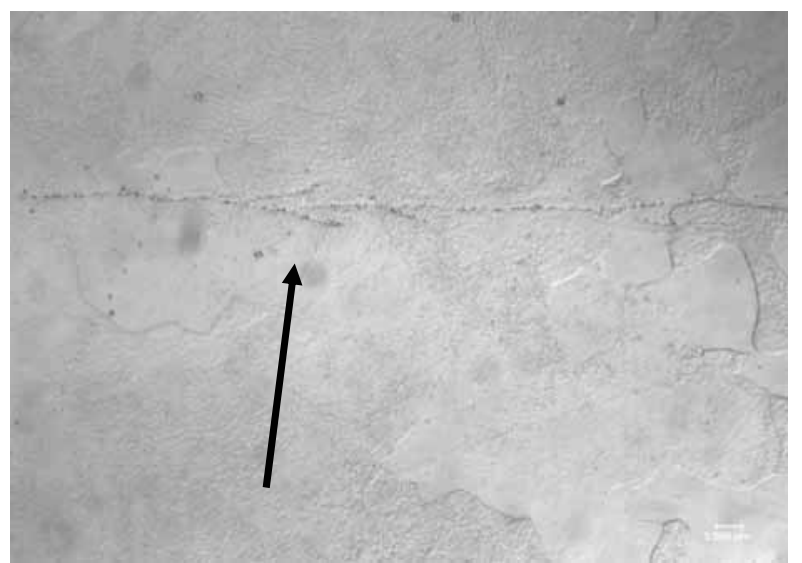

(g)

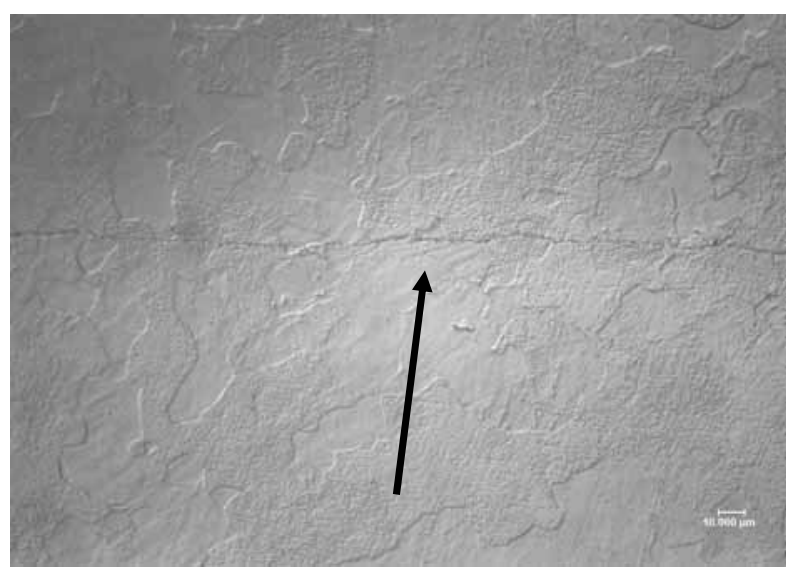

(i)

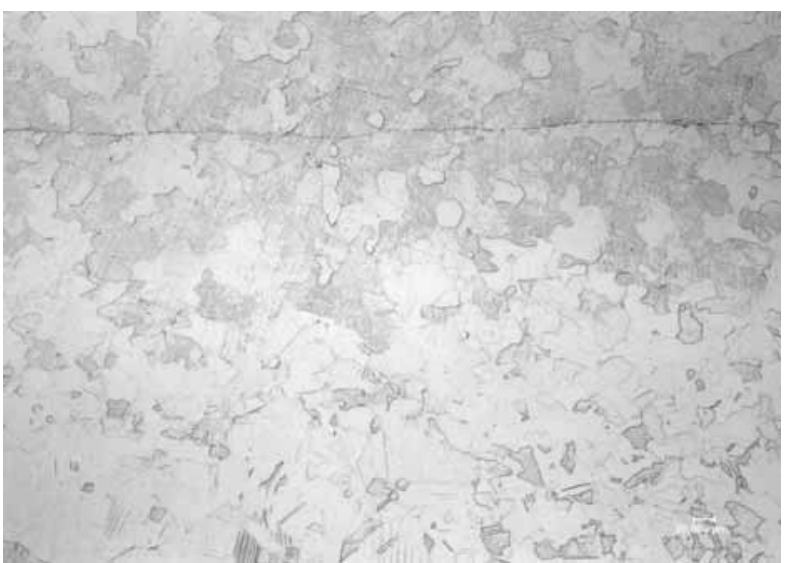

(h)

Figure 10. Transverse cross sections at magnifications of (a) $50 \mathrm{X}$ (b) $100 \mathrm{X}$ (c) $200 \mathrm{X}$ (d) $500 \mathrm{X}$ and (e) $1000 \mathrm{X}$ at 0.02 from end of weld (f) $500 X$ (g) $1000 X$ at 0.06 from end of weld and (h) $200 X$ (i) $500 X$ at the weld center of sample X0047. Note that some disruption, highlighted by the arrows, of the bond line is evident in all three axial locations but little effect on the weld is apparent. 


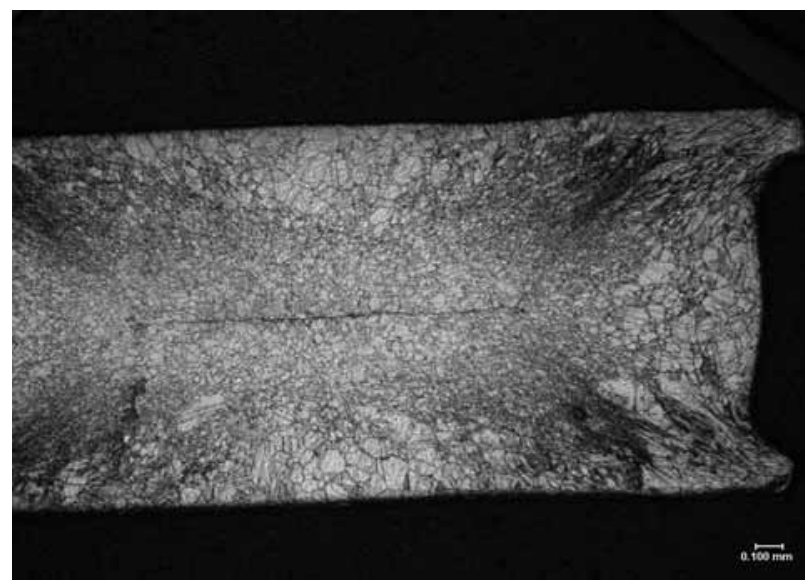

(a)

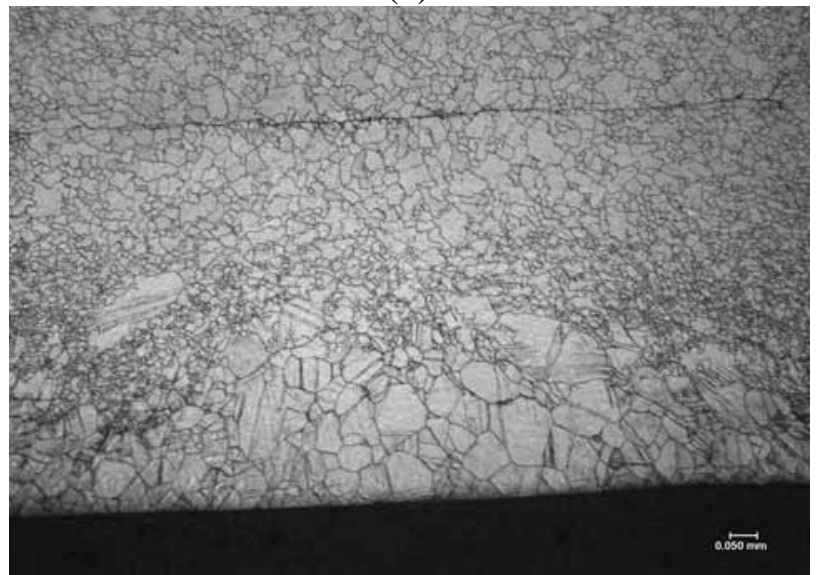

(c)

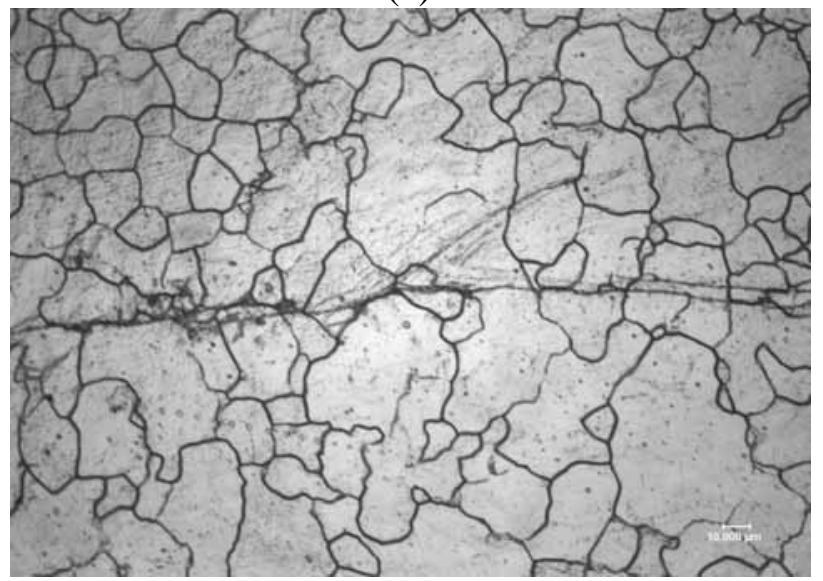

(e)

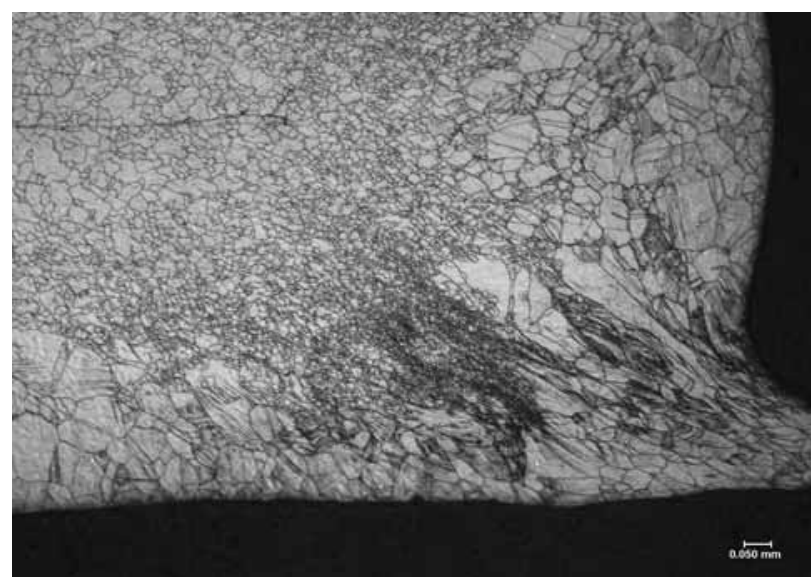

(b)

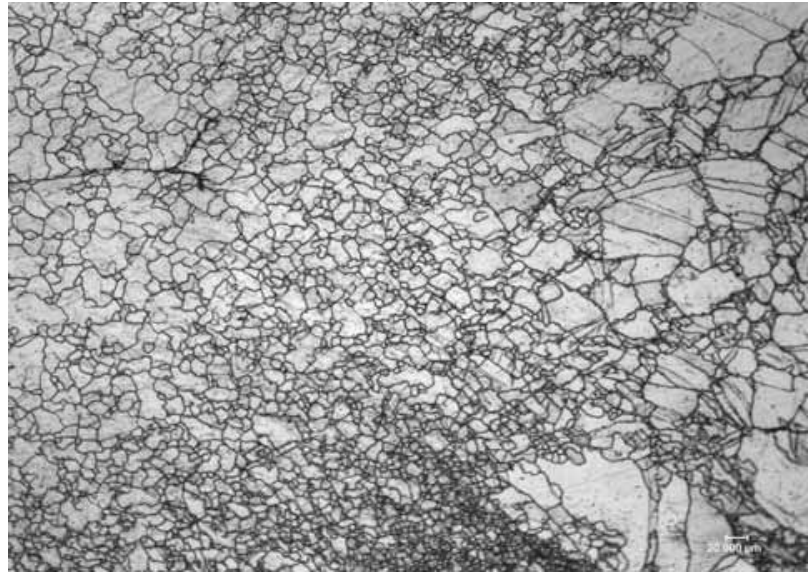

(d)

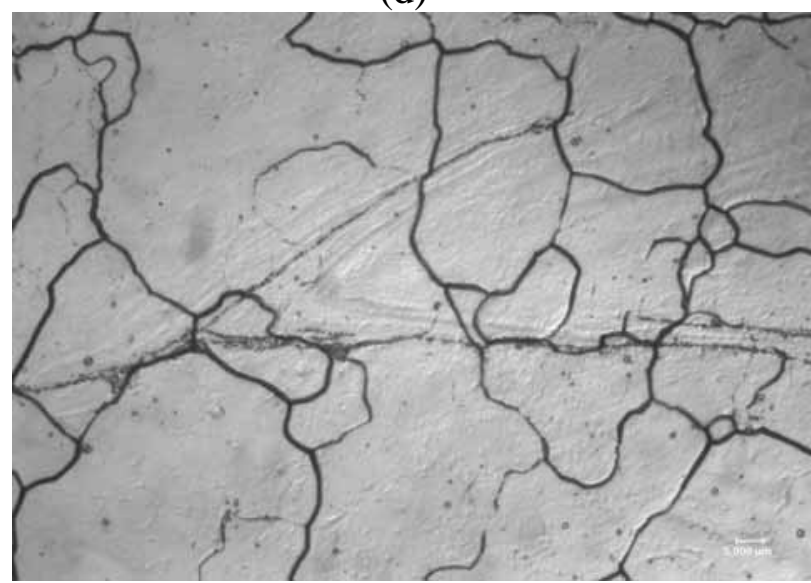

(f)

Figure 11. Sample X0039, nitric acid etchant showing recrystallization and grain growth. The evidence of the scratch is visible at $100 \mathrm{X}$ and higher magnifications. (a) $50 \mathrm{X}$ (b) $100 \mathrm{X}$ (c) $100 \mathrm{X}$ (d) $200 \mathrm{X}$ (e) $500 \mathrm{X}$ and (f) 1000X magnifications. 


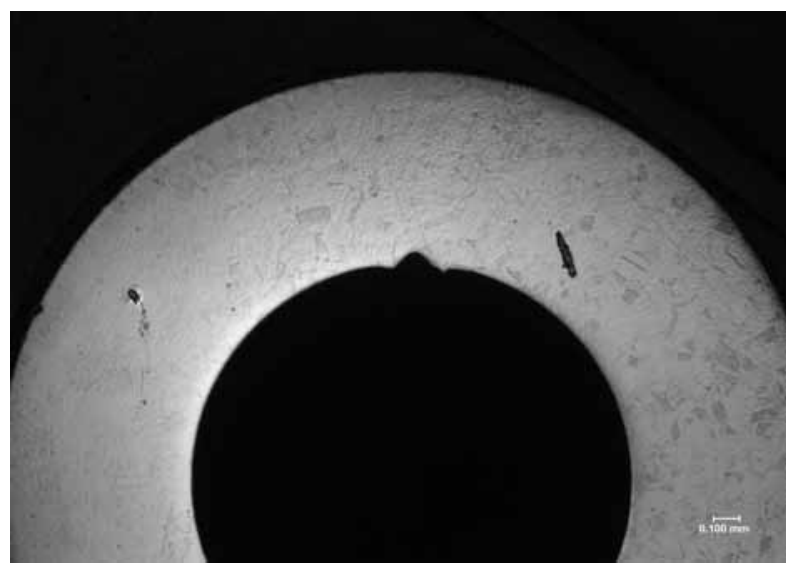

(a)

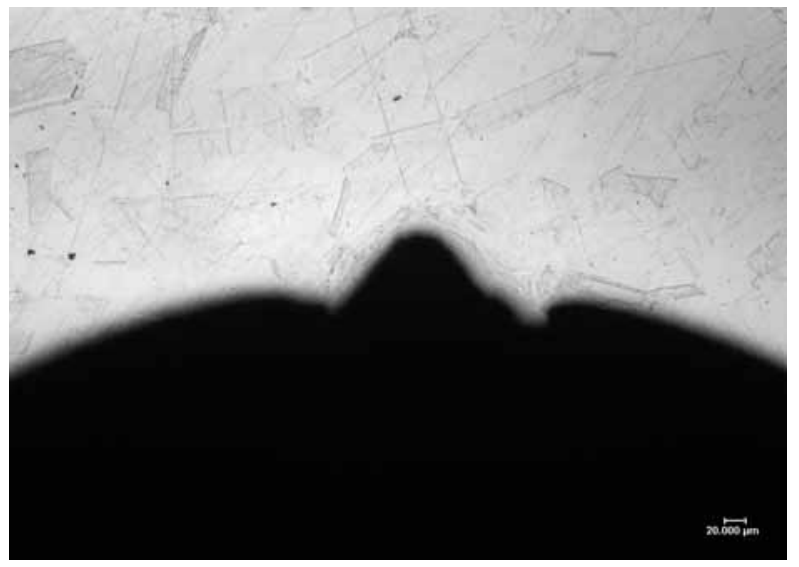

(c)

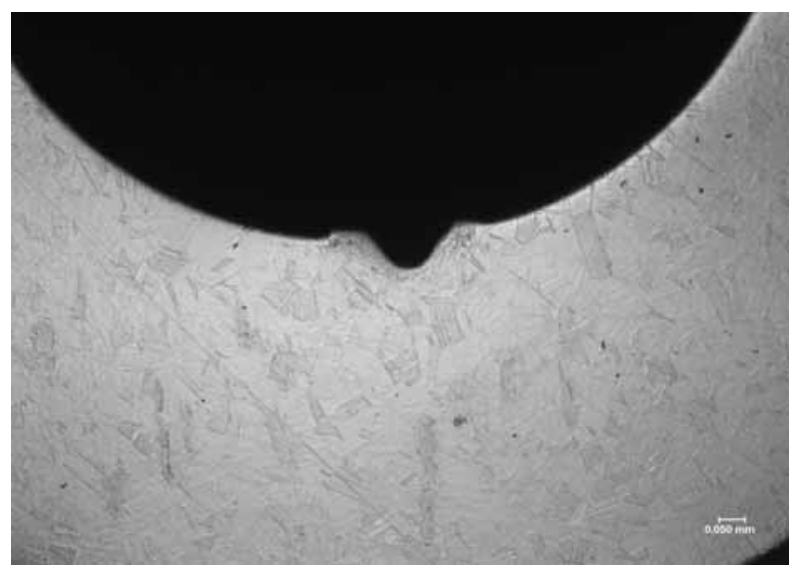

(e)

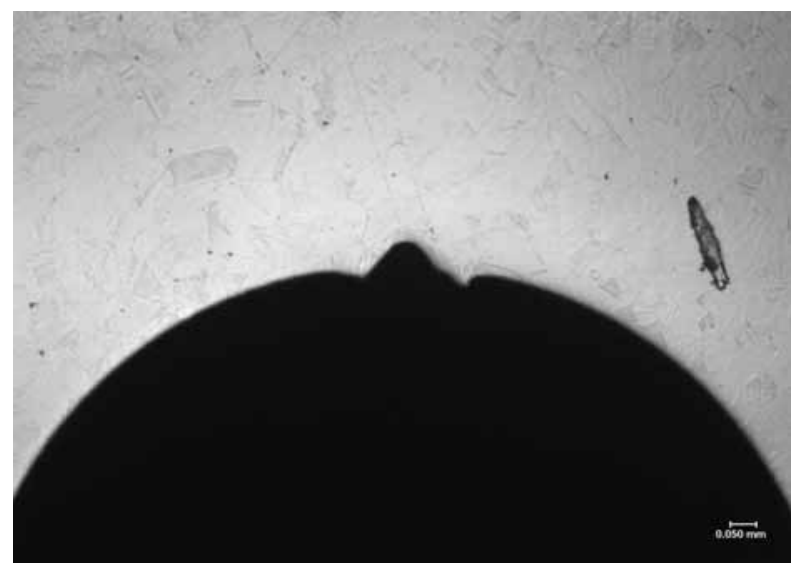

(b)

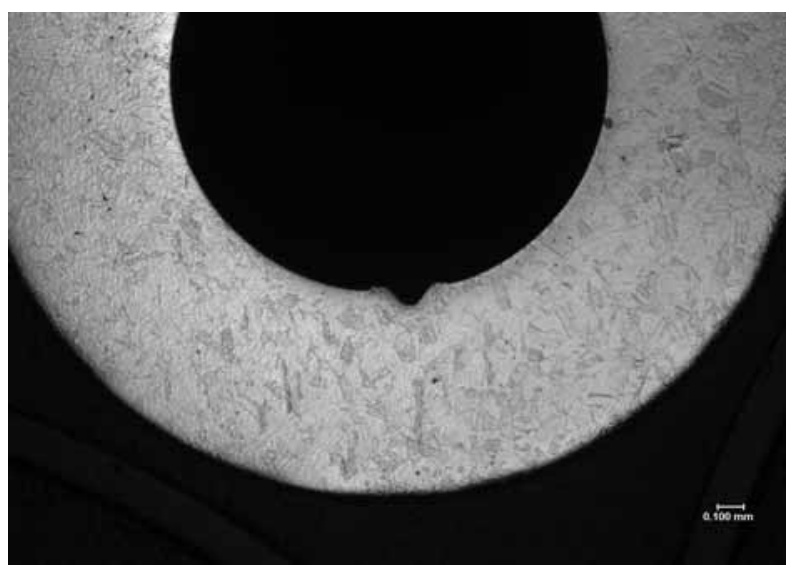

(d)

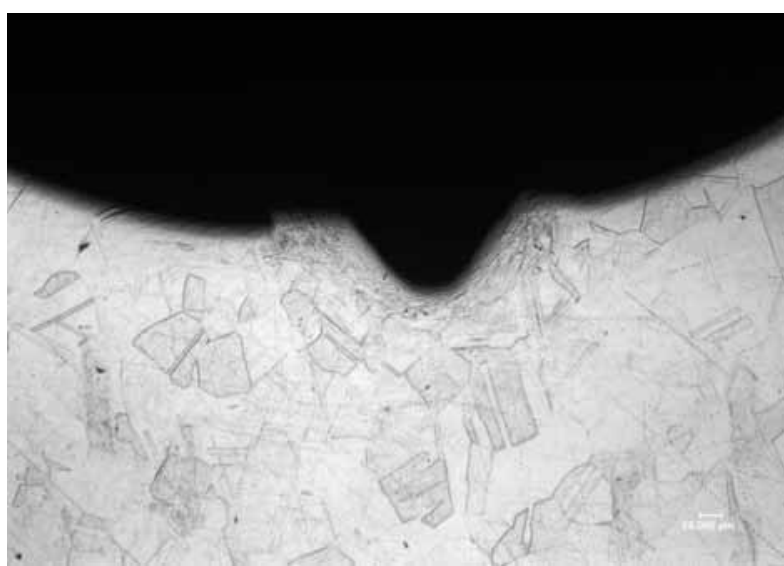

(f)

Figure 12. Transverse cross-sections of the tubes showing the amount of raised metal and the depth of the scratch (a) X0034 50X (b) X0034 100X (c) X0034 500X (d) X0039 50X (e) X0039 100X, and (f) X0039 500X. 


\section{Distribution}

S.L. West SRNL

S. Mazurek SRS

K Arnold KCP

J. Samayoa KCP

E.A Clark SRNL

C. Pretzel SNL

K Hicken SNL

S. Robinson SNL

B. Wilkinson LANL

D Lohmeier LANL

P. Korinko SRNL

B. West SRS

B. Davis LANL

B. Meyer LANL 